\title{
La autorización y clasificación de establecimientos hoteleros en el Ordenamiento Español
}

\author{
Carlos Sanz Dominguez \\ Profesor Colaborador de Derecho Administrativo \\ Universidad de Sevilla
}

SUMARIO. 1. INTRODUCCIÓN. 2. LA APLICACIÓN DEL PRINCIPIO DE LIBERTAD DE EMPRESA Y SUS CONSECUENCIAS. 3. FINALIDAD DEL SISTEMA ADMINISTRATIVO DE AUTORIZACIÓN Y CLASIFICACIÓN DE LOS ESTABLECIMIENTOS HOTELEROS. 3.1. La implantación de modelos de calidad. 3.2. La protección del usuario turístico. 3.3. Protección de los recursos turísticos y sostenibilidad. 3.4. La singular utilización del sistema de clasificación hotelera en la política de control de precios. 4. ORIGEN Y EVOLUCIÓN DE LA CLASIFICACIÓN ADMINISTRATIVA DE LOS ESTABLECIMIENTOS HOTELEROS. 5. CLASIFICACIÓN DE LOS ESTABLECIMIENTOS HOTELEROS EN GRUPOS, CLASES, CATEGORÍAS, MODALIDADES Y ESPECIALIDADES. 5.1. Modelo general de clasificación en dos grupos. 5.2. Modelo general de clasificación en tres grupos. 5.3. Modelos específicos de clasificación. 6. CARACTERÍSTICAS DEL ACTO ADMINISTRATIVO DE AUTORIZACIÓN-CLASIFICACIÓN DE LOS ESTABLECIMIENTOS HOTELEROS. 6.1. Autorización esencialmente reglada. 6.2. Autorización de funcionamiento. 6.3. Autorización de carácter real. 6.4. Autorización operativa. 7. EL ACTO ADMINISTRATIVO DE DISPENSA COMO MANIFESTACIÓN DISCRECIONAL DE LA FACULTAD DE ORDENACIÓN DEL TURISMO A TRAVÉS DE LA CLASIFICACIÓN DE LOS ESTABLECIMIENTOS. 8. ESPECIAL REFERENCIA A LA RECLASIFICACIÓN DE LOS ESTABLECIMIENTOS Y A LA REVOCACIÓN DE LA AUTORIZACIÓN.

\section{Introducción}

La intervención administrativa en el turismo, justificada en la importancia económica y social del fenómeno turístico y en la existencia en su seno de muy relevantes intereses públicos, encuentra en los establecimientos hoteleros su figura paradigmática, pues sobre éstos se concitan dos notas fundamenta- 
les, por una parte, su singular aportación al conjunto de la oferta turística y, por otra, la gran variedad de mecanismos de actuación que la Administración dedica a su ordenación y fomento. De entre estos instrumentos ocupa un lugar destacado la autorización y clasificación administrativa de los alojamientos hoteleros, a cuyo estudio dedicamos el presente trabajo. No obstante, debemos proceder, a modo de introducción, a delimitar conceptualmente los establecimientos turísticos, para analizar a continuación el régimen jurídico y las características fundamentales del mencionado acto administrativo de autorización y clasificación.

Nuestro ordenamiento ha procedido a catalogar y regular un conjunto relevante de actividades empresariales, pertenecientes o vinculadas al denominado sector turístico, otorgándoles la consideración legal de «empresas turísticas». Esta cuestión, lejos de ser meramente semántica o de responder a una clasificación puramente doctrinal, conlleva apreciables consecuencias jurídicas que concretaremos, en este momento, en la aplicación del régimen jurídico especial establecido por la Ley de Turismo de la correspondiente Comunidad Autónoma, así como por la normativa reglamentaria de desarrollo que le sea de aplicación, en función del tipo de empresa de que se trate o la actividad a la que se dedique (reglamentación hotelera; de campamentos de turismo; de apartamentos turísticos; de turismo activo; de intermediación turística; etc.). Además, por su consideración de empresas turísticas, se les impondrá el particular régimen sancionador contenido igualmente en las Leyes de Turismo, con una específica tipificación de infracciones y sanciones, quedando sujetas, asimismo, al ejercicio por parte de la Administración turística de la función inspectora en la materia. No es de extrañar, por tanto, que las Leyes de Turismo reserven parte de su articulado a delimitar el concepto de empresa turística y a relacionar y definir aquellas que considera como tales ${ }^{1}$.

\footnotetext{
${ }^{1}$ Habitualmente las Leyes de Turismo de las Comunidades Autónomas definen de forma directa cuáles sean las empresas que considera turísticas: Las que tienen por objeto de su actividad la prestación, mediante precio, de servicios de alojamiento, restauración, mediación entre los usuarios y los ofertantes de servicios turísticos o cualesquiera otras directamente relacionadas con el turismo que sean calificadas como tales. En algunos casos, las Leyes de Turismo parten de la delimitación del servicio o actividad turística, relacionando éstas, para posteriormente afirmar la consideración de empresas turísticas de todas aquellas que realicen, de forma habitual y profesional, dichas actividades o presten tales servicios. También es frecuente la remisión a una ulterior ampliación de la relación de empresas o actividades que pueden adquirir la condición de "turísticas» por vía reglamentaria, si bien esta fórmula no resulta, a nuestro juicio, acertada, por la implicación de aspectos como la potestad sancionadora o la aplicación del estatuto de empresa turística en su conjunto, sometidas, ambas cuestiones, a reserva de Ley.
} 
Dentro de este conjunto de «empresas turísticas» el ordenamiento configura una determinada clasificación en función de los servicios que presta cada una de ellas, siendo habitual la distinción entre empresas de alojamiento, de restauración, de intermediación turística, y finalmente, de servicios complementarios $^{2}$. A su vez, tanto la doctrina como la normativa vigente distinguen dentro de las empresas de alojamiento las que prestan servicios hoteleros, a las que se denominan alojamientos o establecimientos hoteleros, de las empresas de alojamientos extrahoteleros, entre las que se incluyen los campamentos de turismo o campings, apartamentos turísticos, alojamientos propios del medio rural, ciudades de vacaciones, etc. Citaremos, a modo de ejemplo, lo establecido en la Ley de Turismo del País Vasco (Art. 12):

1. Las empresas a que se refiere el artículo anterior podrán serlo de establecimientos hoteleros o de alojamientos turísticos de carácter extrahotelero.

2. Se entiende por alojamiento turístico extrahotelero los campings, apartamentos turísticos, agroturismo, viviendas turísticas vacacionales y alojamiento en habitaciones de casas particulares destinados a proporcionar albergue mediante precio en épocas, zonas o situaciones de singular significación turística.

Junto a la distinción entre establecimiento hotelero y extrahotelero, es preciso delimitar los conceptos de empresa y establecimiento, cuestión relevante cuando nos encontramos frente a empresas de alojamiento turístico que pueden realizar su actividad mercantil, y por tanto la prestación de servicios turísticos, en diferentes establecimientos ${ }^{3}$. Las Leyes autonómicas de Turismo,

\footnotetext{
${ }^{2}$ La delimitación de la "oferta turística complementaria" es compleja, puesto que en cada Comunidad Autónoma suelen incluirse bajo dicha denominación, diversas actividades empresariales turísticas y, en ocasiones, algunas cuya vinculación con el turismo puede calificarse, al menos, como tangencial. Vid., FERNÁNDEZ RODRÍGUEZ, C., Derecho Administrativo del Turismo, Marcial Pons, Madrid, 2001, p. 195, en la que afirma que "La delimitación de la oferta turística stricto sen$s u$ respecto a la denominada oferta turística complementaria o de entretenimiento no es siempre diáfana, y aún resulta más difusa en las últimas leyes de ordenación turística que califican como actividades turísticas a todas aquellas que directa o indirectamente contribuyen al desarrollo del turismo". Igualmente, CORCHERO, M. y SANDÍN MORA, L., Introducción al Derecho Turístico de Extremadura, Atelier, Barcelona, 2003, p. 45.

${ }^{3}$ FERNÁNDEZ ÁLVAREZ inicia el estudio del régimen jurídico de las empresas turísticas diferenciando entre empresa y establecimiento, afirmando de éste que "cae de lleno dentro del ámbito de aplicación del Derecho administrativo turístico, ya que mientras la regulación de le empresa, en cuanto tal, está contenida en el Derecho Mercantil, la regulación de las actividades de-
} 
como hemos indicado, en su afán por delimitar su campo de acción, han procedido, en su mayoría, a definir (y delimitar) los conceptos fundamentales dentro de dicho ámbito, incluidos los correspondientes a «empresa turística» y «establecimiento turístico». Así, tomando como referencia lo establecido por la Ley Foral de Turismo de Navarra (Art. 12, apdos. 3 y 5, respectivamente):

Empresa turística: la persona física o jurídica que, en nombre propio, de manera habitual y con ánimo de lucro se dedica a la realización de una actividad turística o a la prestación de algún servicio turístico. Se presumirá la habitualidad cuando se realice publicidad de la prestación de servicios turísticos por cualquier medio.

Establecimiento turístico: el conjunto de bienes muebles e inmuebles que, formando una unidad funcional autónoma, es ordenado y dispuesto por el titular para la adecuada prestación de algún servicio turístico.

Esta diferencia entre empresa y establecimiento resulta crucial si tratamos de estudiar el sector hotelero, puesto que la autorización, clasificación e inscripción registral son otorgadas por la Administración con relación a las instalaciones y servicios de cada establecimiento y de forma independiente a las características y forma que presente la empresa que lleve a cabo la explotación turística del mismo ${ }^{4}$. En definitiva, al ordenamiento jurídico le interesa incidir, como se verá supra, sobre la calidad de las instalaciones y servicios que prestan los establecimientos hoteleros, dejando al margen aspectos que conciernen exclusivamente a la persona física o jurídica titular de la explotación mercantil de dichos establecimientos y que, habitualmente, no afectan de forma alguna a la prestación del servicio.

senvueltas por las empresas turísticas a través de sus establecimientos supone ya necesariamente la adecuación de éstos a las reglas y principios contenidos en las ordenaciones turísticas que resulten de aplicación en cada supuesto", en Curso de Derecho Administrativo Turístico, Tomo II, Editorial Nacional, Madrid, 1974, p. 757. Sobre la distinción entre empresa y establecimiento turístico, Vid., igualmente, CALONGE VELÁZQUEZ, A., El turismo: aspectos institucionales y actividad administrativa, Universidad de Valladolid, 2000, pp. 156-158.

\footnotetext{
${ }^{4}$ Esta característica ha traído como consecuencia una reducida o nula intervención administrativa sobre la «empresa hotelera», en comparación, por ejemplo, con las empresas de intermediación turística, puesto que en este segundo caso el ordenamiento ha creído conveniente controlar más la actividad empresarial, es decir, el negocio de mediación entre clientes y prestatarios de servicios turísticos, que el establecimiento en que se lleva a cabo de facto la labor de información y contratación propia de la intermediación turística.
} 
Estas consideraciones previas deben finalizar con una referencia directa al concepto jurídico de establecimiento hotelero. Las primeras disposiciones administrativas que regularon esta actividad, pasaron directamente a su regulación, considerando que se trataba de un concepto sobreentendido y, por tanto, innecesario de definir ${ }^{5}$. Será la Ley $48 / 1963$, de 8 de julio, de Competencias en Materia de Turismo la que aborde por primera vez la cuestión afirmando que (Art. 4):

Se entiende por empresa de hostelería la dedicada de modo habitual o profesional a proporcionar habitación o residencia a las personas, junto o no con otros servicios de carácter complementario.

Con similares términos se incorporó al Estatuto Ordenador de las Empresas y Actividades Turísticas Privadas ${ }^{6}$ (Art. 2,1):

Son empresas de hostelería las dedicadas de modo profesional o habitual, mediante precio, a proporcionar habitación a las personas con o sin otros servicios de carácter complementario.

Las características del establecimiento hotelero (entonces denominado de hostelería) serán, por una parte, su consideración como negocio mercantil o empresarial, debido a la existencia de habitualidad y fin lucrativo, y, por otra, la actividad a la que se dedican, centrada en la prestación del servicio de habitaciones u hospedaje de personas. Con esta configuración aparecerá tanto en la reglamentación estatal de 1983 ("Establecimientos dedicados de modo profesional y habitual al alojamiento de personas mediante precio"), como en las Leyes de Turismo y en las disposiciones reglamentarias reguladoras de los establecimientos hoteleros. Así, para la Ley de Turismo de Cataluña (Art. 40):

\footnotetext{
${ }^{5}$ Así, ni la Orden de 8 de abril de 1939, por la que se establecieron las normas para la apertura, clasificación, fijación de precios y actuación de la industria hotelera, ni el Decreto de 14 de junio de 1957, que la sustituyó, ni la Orden de 19 de julio de 1968, de clasificación de establecimientos hoteleros, procedieron a facilitar un concepto de establecimiento hotelero.

${ }^{6}$ Aprobado por Decreto 231/1965, de 14 de enero. Este Decreto se dictó en desarrollo de la Ley de Competencias en Materia de Turismo, para regular aquellos aspectos que resultaban comunes a los distintos tipos de empresas y establecimientos turísticos, dejando las cuestiones específicas a los reglamentos reguladores de cada actividad turística concreta.
} 
1. Los establecimientos hoteleros son establecimientos que prestan servicio de alojamiento a los usuarios turísticos de forma habitual y mediante precio, como establecimiento único o como unidad empresarial de explotación, tanto si disponen de servicios complementarios como si no disponen de ellos. 2. Las condiciones de prestación del servicio de alojamiento a las que se refiere el apartado 1, que debe incluir en cualquier caso la limpieza diaria de todas las unidades de alojamiento y la inscripción en el Registro de Turismo de Cataluña, han de determinarse por Reglamento.

Delimitado el concepto de establecimiento hotelero, habremos de aplicarle un conjunto de disposiciones dictadas por las Comunidades Autónomas en ejercicio de su potestad de ordenación del turismo, conforme al art. 148,1,18 ${ }^{\circ}$ CE. Este marco normativo autonómico está encabezado por la respectiva Ley de Ordenación del Turismo ${ }^{7}$ y se completa con las correspondientes disposiciones de desarrollo, entre las que debemos destacar los reglamentos de ordenación y clasificación de los establecimientos hoteleros ${ }^{8}$. El contenido de este conjunto de disposiciones normativas nos impulsa a

7 Todas las Comunidades Autónomas cuentan ya con una Ley de Turismo: Ley 12/1999, de 15 de diciembre, del turismo de Andalucía; Ley 6/2003, de 27 de febrero, de turismo de Aragón; Ley 7/1995, de 6 de abril, de ordenación del turismo de Canarias; Ley 5/1999, de 24 de marzo, de ordenación del turismo de Cantabria; Ley 10/1997, de 19 de diciembre, de ordenación del turismo de Castilla y León; Ley 8/1999, de 26 de mayo, de ordenación del turismo de Castilla-La Mancha; Ley 13/2002, de 21 de junio, de turismo de Cataluña; Ley 1/1999, de 12 de marzo, de turismo de la Comunidad de Madrid; Ley 3/1998, de 21 de mayo, de regulación del turismo de la Comunidad Valenciana; Ley 2/1997, de 20 de marzo, de turismo de Extremadura; Ley 9/1997, de 21 de agosto, de turismo de Galicia; Ley 2/1999, de 24 de marzo, general del turismo de las Islas Baleares; Ley Foral 7/2003, 14 de febrero, de turismo de Navarra; Ley 6/1994, de 16 de marzo, de ordenación del turismo del País Vasco; Ley 7/2001, de 22 de junio, de turismo del Principado de Asturias; Ley 11/1997, de 12 de diciembre, de regulación del turismo en la Región de Murcia; Ley 2/2001, de 31 de mayo, de turismo de La Rioja.

${ }^{8}$ Actualmente todas las Comunidades Autónomas cuentan con reglamentación hotelera, excepto Baleares y las Ciudades Autónomas de Ceuta y Melilla. En los tres casos se aplica la normativa estatal contenida en el Real Decreto 1634/1983, de 15 de junio, si bien la Comunidad Autónoma de Baleares sí ha dictado diversas disposiciones que afectan a los establecimientos hoteleros, aunque no a su clasificación. La Rioja, por su parte, cuenta con una única disposición reglamentaria de desarrollo de la Ley de Turismo, en la que se integra la regulación de los establecimientos hoteleros: el Decreto 111/2003, de 10 de octubre, por el que se aprueba el reglamento de desarrollo de la Ley 2/2001, de 31 mayo, de Turismo de La Rioja. 
plantear determinadas consideraciones acerca de la aplicación de la libertad de empresa en este sector empresarial, cuestión que abordaremos en el siguiente apartado ${ }^{9}$.

\section{La aplicación del principio de libertad de empresa y sus consecuencias}

Desde que se inicia el vertiginoso desarrollo de la actividad turística en España, a mediados del pasado siglo, y la intervención de la Administración sobre dicha actividad se hace patente ${ }^{10}$, el ejercicio de las diversas actividades empresariales consideradas «turísticas» queda sometido al cumplimiento de normas reglamentarias que, aún implicando un importante control administrativo, no deja de implantar un sistema fáctico de libertad de empresa, puesto que en ningún caso se excluye del libre ejercicio empresarial actividad turística alguna ${ }^{11}$. Sin embargo la constatación expresa de este principio de libre empresa no se produce hasta el año 1965. En efecto, el Decreto 231/1965, de 14 de enero, por el que se aprueba el Estatuto Ordenador de las Empresas y de las Actividades Turísticas Privadas, dictado en desarrollo de la Ley de Competencias en Materia de Turismo, reconoce, en su art. 8, la libertad de iniciativa empresarial en el sector turístico:

Se declara libre el ejercicio de las actividades propias de las empresas turísticas, sin perjuicio del cumplimiento de los requisitos que correspondan.

\footnotetext{
${ }^{9}$ En palabras de RODRÍGUEZ-PIÑERO, "Ese gran complejo de disposiciones y medidas existentes en la materia, y que ha permitido a algunos hablar imprecisamente de un «Derecho turístico", suponen en el plano de la actividad económica privada relacionado con el turismo limitaciones importantes a la libertad económica y, en el plano jurídico, la configuración de obligaciones jurídico-públicas y la existencia de disposiciones imperativas que limitan sensiblemente el juego de la autonomía privada", en "La intervención administrativa en la empresa hotelera", en Primer Congreso Italo-Español de Profesores de Derecho Administrativo, Ministerio de Información y Turismo, Madrid, 1970, p. 207.

${ }^{10}$ La doctrina considera el Real Decreto de 6 de octubre de 1905, por el que se crea la «Comisión Nacional para el fomento del Turismo», como el inicio de la intervención administrativa sobre el turismo. Sin embargo, será a partir de mediados de los años cincuenta cuando dicha intervención cobre un mayor relieve, alcanzando su cenit con la Ley de Competencias en Materia de Turismo (1963) y el Estatuto Ordenador de Empresas y Actividades Turísticas Privadas (1965).

11 Sobre la aplicación de la libertad de empresa en el sector turístico, Vid., SANZ DOMÍNGUEZ, C., Régimen jurídico-administrativo de la intermediación turística, Consejería de Turismo, Comercio y Deporte, Sevilla, 2005, especialmente, pp. 35-136.
} 
Posteriormente este principio se incorporó a determinados reglamentos sectoriales, como el correspondiente a los restaurantes, aprobado por Orden Ministerial de 17 de marzo de $1965^{12}$; a las cafeterías, contenido en la Orden Ministerial de 18 de marzo de $1965^{13}$; a los campamentos de turismo, regulado por Orden Ministerial de 28 de julio de $1966^{14}$; o, finalmente, a las ciudades de vacaciones, reglamentadas por Orden Ministerial de 28 de octubre de $1968^{15}$. No ocurre así con los establecimientos hoteleros, en sus sucesivas reglamentaciones, aunque en la práctica siga vigente dicho principio, contenido, como se ha indicado, con carácter general para todas las empresas turísticas en el Estatuto Ordenador de Empresas y Actividades Turísticas Privadas.

Este principio de libertad de empresa adquirirá su plasmación constitucional a través del art. $38 \mathrm{CE}$, por el que "se reconoce la libertad de empresa en el marco de la economía de mercado”. De esta forma, además de alcanzar el máximo rango normativo, se hace extensivo el derecho a la libre iniciativa empresarial a todos los sectores de la economía, salvo que, en aplicación del art. 128,2 CE se efectúe algún tipo de reserva de recursos o servicios esenciales a favor del sector público, a la vez que se garantiza un contenido esencial de la libertad de empresa y se reserva a la Ley su regulación (Art. 53,1 CE) ${ }^{16}$.

12 Art. 5: "Se declaran libres las actividades propias de las empresas de restaurante, tanto en lo que se refiere a la posibilidad de su ejercicio por cualquier persona, como al lugar en que puedan instalarse los establecimientos, sin perjuicio del cumplimiento de los requisitos que se previenen en la presente ordenación".

13 Art. 5: "Se declaran libres las actividades propias de las empresas de cafetería, tanto en lo que se refiere a la posibilidad de su ejercicio por cualquier persona, como al lugar en que puedan instalarse los establecimientos, sin perjuicio del cumplimiento de los requisitos que se previenen en la presente ordenación"

14 Art. 4: "Se declara libre el ejercicio de las actividades propias de las empresas de alojamiento en campamentos de turismo sin perjuicio del cumplimiento de los requisitos que se previenen en la presente ordenación”.

15 Art. 4: "Se declara libre la industria de hospedaje en ciudades de vacaciones tanto en lo que se refiere a la posibilidad de su ejercicio por cualquier persona como en cuanto al lugar en que puedan instalarse los establecimientos, sin perjuicio del cumplimiento de los requisitos y trámites que se establecen en la presente ordenación y demás disposiciones aplicables".

16 Vid. SANZ DOMÍNGUEZ, C., Régimen jurídico-administrativo de la intermediación turística, op. cit., pp. 45-78. 
Sin embargo, el instrumento de reserva de recursos o servicios a favor del sector público no ha sido activado en ningún caso, en relación con el sector turístico $^{17}$.

El ejercicio de la libertad de empresa dentro del ámbito del turismo será regulado finalmente por la legislación autonómica dictada en aplicación de la competencia exclusiva sobre promoción y ordenación del turismo (Art. $148,1,18^{\circ} \mathrm{CE}$ ), particularmente, como hemos indicado, por la Ley de Turismo y las disposiciones reglamentarias de desarrollo ${ }^{18}$. En algunos casos, las propias Leyes de Turismo contienen una declaración formal de reconocimiento de la libertad de iniciativa económica en el sector turístico ${ }^{19}$.

Este reconocimiento general de la libertad de empresa no garantiza, como ha recordado el Tribunal Constitución el "derecho a acometer cualquier empresa" ${ }^{20}$, sino que a través de las Leyes de Turismo y de las disposiciones re-

\footnotetext{
${ }^{17}$ Aunque ello no ha impedido la existencia de iniciativa pública en el sector turístico. Vid., a este respecto, los trabajos de PELLEJERO MARTÍNEZ, C., El Instituto Nacional de Industria en el Sector Turístico, Universidad de Málaga, 2000 y La intervención del Estado en el sector turístico: De la Comisión Nacional a la Empresa Nacional de Turismo, Junta de Andalucía, Sevilla, 1986.
}

18 RIVERO YSERN, J.L., afirma, en efecto, refiriéndose a la Ley de Turismo de Andalucía, que "Parte la Ley de la libertad de prestación de los servicios turísticos sin más limitaciones que las derivadas de las normas legales y reglamentarias que sean de aplicación. No obstante, quienes se dediquen en nombre propio y de manera habitual y remunerada a la prestación de algún servicio turístico deberán estar inscritos en el Registro de Turismo de Andalucía, así como, en su caso, hallarse en posesión de las correspondientes licencias o autorizaciones, otorgadas por la Administración competente", en "Notas sobre la Ley 12/1999, de 15 de diciembre, reguladora del turismo en Andalucía”, en Documentación Administrativa, núm. 259-260, 2001, p. 207.

${ }^{19}$ Así ocurre en las Leyes de Turismo de Andalucía (Art. 28), Aragón (Art. 25), Canarias (Art. 13), Cataluña (Art. 35), Comunidad de Navarra (Art. 13), Comunidad de Valencia (Art. 18,2) e Islas Baleares (Art. 9). A modo de ejemplo, el art. 25 LT Aragón determina que "El ejercicio de la actividad empresarial es libre, sin más limitaciones que las establecidas en las Leyes, bajo la forma de empresario individual o colectivo, de acuerdo con la legislación civil y mercantil". Este tipo de declaraciones no aporta, empero, ningún valor o garantía adicional en relación con lo establecido en el art. $38 \mathrm{CE}$.

${ }^{20}$ Vid. STC 83/1984, de 24 de julio y STC 84/1993, de 8 de marzo. Recientemente, en su Sentencia 112/2006, de 5 de abril, el Tribunal Constitucional ha aplicado este principio para rechazar el recurso presentado contra la Ley 21/1997, de 3 de julio, Reguladora de las Emisiones y Retransmisiones de Competiciones y Acontecimientos Deportivos. 
glamentarias que las desarrollen, se aplicará y reconocerá dicho principio a la actividad empresarial turística, en la que no se ha producido, como se ha indicado supra, ninguna reserva a favor del sector público. De esta forma, serán las Leyes de Turismo, en aplicación del principio de reserva de Ley, las que establecerán, respetando el contenido esencial del derecho a la libertad de empresa, los límites y condiciones de su ejercicio, sometiendo éste al cumplimiento de un conjunto de requisitos y obligaciones; a la necesidad de obtener autorización o licencia administrativa previa; a una normativa reglamentaria incisiva que procede a imponer estándares, requisitos, condicionantes y mandatos en función de una previa delimitación de categorías, grupos o modalidades de establecimientos; a la inscripción registral preceptiva; a la función inspectora por parte de la Administración turística dirigida a verificar el cumplimiento de la normativa turística aplicable; al ejercicio de la potestad sancionadora por parte de la Administración; etc ${ }^{21}$. En definitiva, el ordenamiento impone un sistema de intervención administrativa especialmente intenso sobre las empresas turísticas en general y, particularmente, sobre los establecimientos hoteleros, dirigido a la protección de los intereses públicos presentes y a la consecución de los fines marcados por las Leyes de Turismo, según analizaremos a continuación. Sin duda, de todos los instrumentos mencionados serán la autorización y clasificación los que tengan una mayor incidencia en la ordenación de los establecimientos y, por tanto, en el ejercicio de la iniciativa empresarial en el sector, y fundamentarán el uso de las restantes potestades administrativas (inspección, fomento, registro, potestad sancionadora, etc.).

\section{Finalidad del sistema administrativo de autorización y clasificación de los establecimientos hoteleros}

El sistema de autorización y clasificación de los establecimientos hoteleros que implanta nuestro ordenamiento forma parte de la facultad de ordenación del turismo, que la Constitución (Art. 148,1,18ํㅜ) y los Estatutos de Au-

${ }^{21}$ Para CALONGE VELÁZQUEZ, A., "Conforme al principio de legalidad la Administración pública precisa de un respaldo normativo específico para poder actuar una cualquiera de las técnicas de limitación de derechos y, en cuanto se trata de restricciones a la libertad de determinación que el derecho subjetivo consagra, ese respaldo normativo, explícito y preciso que apodere a la Administración ha de cubrirse, en último extremo, con una Ley formal”. El turismo: aspectos institucionales y actividad administrativa, Op. cit., p. 173. Sobre la potestad sancionadora y su régimen jurídico en el campo del turismo, Vid. REBOLLO PUIG, M., "Legislación autonómica de disciplina turística”, en Revista Andaluza de Administración Pública, núm. 8, 1991, pp. 29-102. 
tonomía atribuyen a las Comunidades Autónomas. Implica, por tanto, la aplicación de un conjunto de restricciones, con forma de mandatos y prohibiciones, que delimitan el contenido de la libre actuación empresarial en el subsector hotelero, bajo la justificación de la salvaguarda de determinados intereses públicos ${ }^{22}$. Únicamente la existencia de intereses públicos o la presencia de intereses privados que el ordenamiento considera dignos de especial protección y amparo sirven de fundamento a la imposición de limitaciones al libre ejercicio de la señalada actividad empresarial. Serán pues las Leyes autonómicas de Turismo, cumpliendo con las exigencias de la reserva de Ley en la regulación de la libertad de empresa (Art. 53,1 CE), las que disciplinen la autorización previa y la clasificación administrativa de los establecimientos hoteleros, en cumplimiento de los fines y objetivos de ordenación fijados por ellas mismas.

\subsection{La implantación de modelos de calidad}

Una de las principales finalidades que marcan las Leyes de Turismo será el desarrollo y fomento del turismo por medio de la implantación de modelos de calidad en la prestación de servicios y en las instalaciones de los establecimientos, que redunden en la máxima competitividad de las empresas ${ }^{23}$. Este proceso de implantación de estándares de calidad mediante instrumentos jurídico-públicos se desarrolla en tres fases. En una primera, la Administración establece, con carácter general, un sistema de calidad mediante el ejercicio de su potestad normativa, subordinada a las prescripciones impuestas por la Ley de Turismo, creando auténticas reglamentaciones técnicas (por ejemplo, la reglamentación hotelera). En un segundo momento se produce la aplicación de la reglamentación con carácter previo al ejercicio de la actividad sometida a autorización y clasificación. La Administración comprueba el cumplimiento

22 Pese a que es evidente la necesidad de que los poderes públicos garanticen determinados intereses públicos presentes en la actividad turística, gran parte de la doctrina fundamenta dicho interés exclusivamente en fines puramente economicistas. Así, LUENGO YUSTE, J., afirma que "Naturalmente el turismo es una gran fuente de divisas y viene a ser en muchos países un medio para equilibrar la balanza de pagos o la balanza comercial. La necesidad de defender una industria de tales características con repercusión práctica en la generalidad de los distintos aspectos de la vida de los países, ha impulsado a casi todos los Estados actuales a intervenir directamente, mediante su potestad normativa", en Legislación Turística y Derecho Administrativo, Editorial Universitas, Madrid, 1992, p. 20.

${ }^{23}$ Vid., con referencia a la Comunidad extremeña, CORCHERO, M. y SANDÍN MORA, L., Introducción al Derecho Turístico de Extremadura, op. cit., pp. 45-50. 
de la normativa y conforme a los criterios de calidad fijados en ella procede a otorgar la clasificación que deba corresponder a cada establecimiento. Con frecuencia, el ordenamiento impone un procedimiento de clasificación previo al inicio de las obras de construcción, implantación o ampliación de los establecimientos hoteleros. Finalizadas las obras y comprobada su adecuación al proyecto inicialmente valorado por la Administración, se confirma la clasificación otorgada provisionalmente, convirtiéndose en definitiva. En una tercera fase le corresponde a la Administración la función de corroborar el continuo mantenimiento de los requisitos que se tuvieron en cuenta para el otorgamiento de la autorización y clasificación correspondiente. Esta tercera fase se extenderá a lo largo de todo el tiempo en que el establecimiento permanezca abierto al público, conforme a su configuración como autorización de funcionamiento, según se verá más adelante, e implica la disponibilidad de relevantes facultades administrativas de intervención, tales como, función inspectora; ejercicio de la potestad sancionadora; facultad de revocación; cierre cautelar del establecimiento; adaptación preceptiva a las modificaciones ulteriores de la reglamentación técnica; etc ${ }^{24}$.

Todo el proceso de implantación y aseguramiento de los requisitos, particularmente respecto a las instalaciones y servicios, correspondientes a cada categoría va dirigido a la consecución de la calidad en la prestación de servicios al usuario turístico por parte del establecimiento de alojamiento hotelero. Así, el art. 34 LT Galicia, determina, en relación con las bases de clasificación:

1. Todos los establecimientos hoteleros deberán cumplir la normativa vigente en materia de construcción y edificación, instalación y funcionamiento de maquinaria, sanidad y consumo y seguridad e higiene.

2. A los efectos de la clasificación de los hoteles en la categoría que soliciten ser incluidos se valorará la calidad de la oferta en instalaciones y servicios, las condiciones de equipamiento de las habitaciones y cuartos de baño, las prestaciones para las personas discapacitadas y una recepción suficiente y permanentemente atendida, así como las dependencias de uso común para los clientes y los servicios complementarios.

${ }^{24}$ Vid., al respecto, BLANQUER CRIADO, D., "La ordenación jurídica de la calidad del turismo", en SOSA WAGNER, F. (Coord.), El Derecho Administrativo en el umbral del siglo XXI, Tirant lo Blanch, Valencia, 2000, especialmente 3154-3155. 
Los reglamentos de ordenación y clasificación de los establecimientos hoteleros, desarrollando las respectivas Leyes de Turismo, detallan los criterios para el otorgamiento de la categoría, implantando determinados «patrones» o «modelos» de calidad. Así, el art. 21,5 del Reglamento de Andalucía ${ }^{25}$, determina que:

La categoría de los establecimientos hoteleros será fijada teniendo en cuenta la calidad de las instalaciones y servicios, de conformidad con los requisitos y las condiciones previstas en este Decreto.

No obstante el sistema administrativo de clasificación de los establecimientos hoteleros adolece de un marcado carácter estático, al fundamentarse en requisitos materiales y referirse, de forma primordial, a valores cuantitativos (aspectos físicos o materiales fácilmente medibles, como las dimensiones de las unidades de alojamiento, cuartos de baño, zonas comunes, etc.), marginando valoraciones más cercanas a aspectos cualitativos (calidad como satisfacción del cliente; calidad objetiva; etc.). Este aspecto ha sido destacado por la Organización Mundial del Turismo indicando, además, la necesidad de aunar "aspectos físicos y cuantitativos de los establecimientos hoteleros (que responderían a la pregunta de qué se suministra)" a "aspectos cualitativos de la oferta de servicios hoteleros (que responden sobre todo a la pregunta general de cómo se suministran)" 26 .

Para completar estas deficiencias del sistema administrativo de clasificación hotelera, la Administración impulsa actuaciones adicionales, normalmente mediante instrumentos facultativos dirigidos a incentivar, más que a imponer, políticas de calidad en los establecimientos hoteleros: implantación de distintivos adicionales de calidad; otorgamiento de premios a la calidad; ayudas y subvenciones dirigidas a la implantación de modelos de calidad; etc. Entre estas medidas debemos destacar especialmente las impulsadas por la Administración central a través del Plan Integral de Calidad del Turismo Español (PICTE), como es la concesión de la "Q calidad turística» a través del Instituto para la Calidad Turística Española (ICTE) ${ }^{27}$.

${ }^{25}$ Decreto 47/2004, de 10 de febrero.

${ }^{26}$ Punto 4 del informe Nuevas Tendencias y Medidas en el sector hotelero, Conferencia Mundial de San Petesburgo, abril de 2004.

${ }^{27}$ Vid., TUDELA ARANDA, J., "La problemática jurídica de la calidad turística”, en MELGOSA, F.J., Derecho y Turismo, Universidad de Salamanca, 2004, pp. 81-102. 


\subsection{La protección del usuario turístico}

El objetivo de calidad, marcado por las Leyes de Turismo y los Reglamentos de ordenación y clasificación de los establecimientos hoteleros de las diferentes Comunidades Autónomas, nos dirige hacia una nueva finalidad: la protección del usuario turístico ${ }^{28}$. A modo de ejemplo, el art. 4 de la LT Región de Murcia incluye entre los principios rectores de la actuación administrativa:

La protección del usuario de los servicios turísticos, mediante la configuración de su régimen de derechos y obligaciones.

Este objetivo, presente en la ordenación hotelera de todas las Comunidades Autónomas, conecta directamente con el principio constitucional de protección a los consumidores y usuarios (Art. $51 \mathrm{CE}$ ) del que resulta una mera plasmación sectorial, aunque con las connotaciones especiales que concurren en el usuario turístico. Este principio de protección del usuario turístico ha dado lugar al nacimiento, a través de las Leyes de Turismo, de un auténtico «derecho a la calidad» ${ }^{29}$, configurado como un derecho subjetivo del usuario turístico a percibir los servicios contratos en las condiciones adecuadas de calidad en función del contenido del contrato establecido entre proveedor y usuario ("Derecho a la calidad de los bienes y servicios conforme a la contratación efectuada", según establece el art. 31 LT Navarra); las condiciones y limitaciones impuestas legal y reglamentariamente al establecimiento y, finalmente, conforme a la clase y categoría que ostente el establecimiento contratado. Así, para la LT Aragón el usuario turístico tiene derecho a "recibir los servicios turísticos en las condiciones ofertadas o pactadas, debiendo corresponder los servicios con la categoría del establecimiento" (Art. 21,c). Sin embargo, será el art. 40 de la Ley General de Turismo de Baleares el que delimite con mayor precisión, a nuestro juicio, este derecho a la calidad:

\footnotetext{
${ }^{28}$ Para SABÁN GODOY, A., la política y la actuación normativa y administrativa crean un "círculo protector de los usuarios", en "Administraciones Públicas y sector turístico", en SORIANO GARCÍA, J.E. (Dir.), Congreso de Derecho Administrativo Turístico, Universidad de Extremadura, Cáceres, 2002, p. 20.

${ }^{29}$ Sobre este denominado «derecho a la calidad», Vid., SANZ DOMÍNGUEZ, C., La calidad del turismo desde la perspectiva de la Administración Pública, VIII Semana Europea de la Calidad, Edición Digital@tres, Sevilla, 2003.
} 
Todo usuario de servicios turísticos tiene derecho a que los bienes y los servicios que adquiera sean de la categoría y requerimientos legales contratados o, si no hay pacto, de aquella calidad que guarde proporción directa con la categoría de la empresa o establecimiento turístico.

Destacaremos en este punto la vinculación que se establece entre calidad y clasificación y la protección que a dicho nexo otorga el Derecho Administrativo. En efecto, al establecerse un sistema administrativo de clasificación, la Administración pública adopta la función de garante o, al menos, de supervisión respecto al cumplimiento de las condiciones impuestas a través de la clasificación hotelera a los establecimientos. De este modo, el ordenamiento impone un sistema jurídico-público de resolución de quejas por medio de las hojas de reclamaciones que el usuario remite a la Administración para su tramitación y resolución ${ }^{30}$ y otorga a la Administración la función inspectora de los establecimientos $^{31}$ y el ejercicio, en su caso, de la potestad sancionadora contra las empresas infractoras ${ }^{32}$. Precisamente, los servicios de inspección turística asumen una especial misión en la vigilancia de la calidad de los establecimientos en relación con la categoría concedida por la Administración. Así se pone especialmente de relieve en el Plan de Turismo de Castilla y León (2000-2006):

${ }^{30} \mathrm{El}$ art. 20 LT Canarias detalla el sistema de reclamaciones en los siguientes términos: "1. Las empresas turísticas vienen obligadas a tener en cada establecimiento las hojas de reclamaciones a disposición de sus clientes. La persona encargada del establecimiento estará obligada a facilitar las hojas de reclamación al usuario turístico que lo solicite y a facilitarle, además, las explicaciones necesarias para su adecuada cumplimentación. 2. En el establecimiento se anunciará de forma bien visible e inequívoca, expresada en castellano, inglés, alemán y otro idioma a elegir, la existencia de hojas de reclamación a disposición de los clientes. 3. Tanto las características de las hojas de reclamación como el procedimiento de tramitación de las reclamaciones se determinará reglamentariamente. En todo caso, cuando la queja se formule directamente ante una Administración pública ésta extenderá recibo de la misma. Copia de todas las quejas y reclamaciones será trasladada a la inspección turística de la Administración autonómica. Al reclamante se le notificará la resolución que se adopte como consecuencia de su queja”.

31 Así, a tenor del art. 62,1 LT Baleares, corresponde a la inspección, entre otras funciones "Comprobar el cumplimiento por las empresas, actividades y establecimientos turísticos de las obligaciones legales o reglamentariamente impuestas".

${ }^{32} \mathrm{El}$ incumplimiento de los requisitos de clasificación queda tipificado como infracción administrativa en las Leyes de Turismo. Así, por ejemplo, el art. 75,1 LT Canarias, considera como infracción grave "El incumplimiento o alteración de las condiciones esenciales de la autorización de que esté provista la empresa o actividad, cuando tales condiciones hayan servido de base para el otorgamiento de dicha autorización o para la clasificación turística del establecimiento o actividad". 
La inspección turística es el primer mecanismo del que dispone la Administración para realizar un control de calidad evitando que el cliente reciba unos productos o servicios inadecuados, impulsando de esta forma asegurar la cualificación de los servicios prestados, mediante la vigilancia del cumplimiento de las normas administrativas de clasificación de los establecimientos turísticos. (...) Puede afirmarse que las funciones de inspección en el sector turístico tienen como última finalidad lograr la calidad en la prestación de los servicios turísticos en los niveles requeridos por los turistas.

Sin embargo, debemos insistir nuevamente, en que el binomio clasificación-calidad se activa desde el momento mismo en que la Administración otorga la correspondiente autorización y clasificación a cada establecimiento hotelero, manteniéndose mientras éstos permanezcan prestando servicios a los usuarios turísticos.

\subsection{Protección de los recursos turísticos y sostenibilidad}

Por otra parte, debemos subrayar entre los objetivos o finalidades impuestos por la Ley que se vinculan a la autorización y clasificación de los establecimientos hoteleros, la protección de los recursos turísticos en el marco del desarrollo sostenible y, por tanto, del medio ambiente en sus distintas manifestaciones ${ }^{33}$. El principio de desarrollo sostenible o sostenibilidad impregna la legislación turística de los últimos años y, particularmente, las Leyes de Turismo. Si tomamos como ejemplo la Ley de Turismo de Aragón, encontramos dos referencias directas al desarrollo sostenible. Así, en primer lugar, incluye, entre los principios de la política turística autonómica (Art. 4):

Proteger el patrimonio natural y cultural y los demás recursos turísticos de la Comunidad Autónoma, conforme al principio del desarrollo turístico sostenible.

Más adelante, la Ley aplica dicho principio a la actuación de las diferentes Administraciones Públicas, determinado que (Art. 16):

Las Administraciones públicas con competencias sobre turismo estimularán la mejora de la calidad y de la competitividad de la oferta turística, res-

\footnotetext{
${ }^{33}$ Sobre la relación entre turismo, medio ambiente y el papel que al respecto asume la Administración, Vid., ROCA ROCA, E., "Administración pública y turismo", en Documentación Administrativa, núm. 259-260, 2001, pp. 7-25.
} 
petando el patrimonio natural y cultural, y promoviendo el reequilibrio territorial para la consecución de un desarrollo turístico sostenible.

Previsiones similares se incluyen en las restantes Leyes autonómicas así como en los Reglamentos de ordenación y clasificación de los establecimientos hoteleros. Sin embargo, en éstos aún son muy reducidas, a nuestro juicio, las medidas y limitaciones impuestas en beneficio del medio ambiente y del desarrollo sostenible. En todo caso debemos hacer hincapié en la facultad que posee la Administración autonómica de controlar el cumplimiento de los condicionantes ambientales por medio de la autorización y clasificación de los establecimientos hoteleros, imponiendo dichas previsiones, bien como requisitos comunes a los establecimientos, bien en función de la categoría que se vaya a solicitar u otorgar.

Entre las medidas de protección ambiental a implantar sobre los establecimientos hoteleros, podemos destacar las siguientes ${ }^{34}$ :

- Control ambiental genérico que puede efectuarse a través de la licencia municipal de primera utilización, como prevé al art. 53,2,a) $\mathrm{RH}$ Andalucía ${ }^{35}$.

- Instrumentos de control ambiental previstos en la Legislación de Protección Ambiental correspondiente ${ }^{36}$.

- Condiciones y requisitos relacionados con la protección del medio ambiente, particularmente respecto al abastecimiento de agua potable,

\footnotetext{
${ }^{34}$ En orden a la regulación de condicionantes ambientales para su cumplimiento por parte de los establecimientos hoteleros resultan de gran interés las aportaciones efectuadas en BOSCH CAMPRUBÍ, R., PUJOL MARCO, LL., SERRA CABADO, J. y VALLESPINÓS RIERA, F., Turismo y Medio Ambiente, Ceura, Madrid, 1998, pp. 188-192, particularmente al tratar "la acción medioambiental de las empresas turísticas y sus efectos" y los "ejemplos de medidas de protección medioambiental en las empresas turísticas", en la que se reflejan los casos de Canadian Hotels \& Resorts y Riu Hotels.

${ }^{35}$ Según determina este artículo, la solicitud de inscripción definitiva en el Registro de Turismo de Andalucía requiere, entre otros documentos, la licencia municipal de primera utilización "en la que conste la adecuación del establecimiento hotelero a la normativa urbanística y medioambiental que le sea de aplicación y, en su caso, a la de protección del patrimonio histórico, así como el cumplimiento de las medidas de seguridad y, en especial, las de protección contra incendios".

${ }^{36}$ La Ley de Turismo de Andalucía, en su disposición adicional tercera incluyó a los establecimientos hoteleros entre los que debían requerir informe de calificación ambiental conforme a la Ley 7/1994, de 18 de mayo, de Protección Ambiental de Andalucía.
} 
utilización de energías renovables y alternativas, implantación de sistemas de ahorro energético, reutilización de aguas pluviales y aguas grises, etc.

- Estricto cumplimiento de las previsiones establecidas respecto a la eliminación de residuos sólidos y líquidos, con prohibición de vertidos contaminantes.

- Incentivar el cumplimiento de condiciones ambientales más estrictas como instrumento de compensación para el otorgamiento de dispensa de algún requisito correspondiente a la categoría solicitada. Esta técnica es utilizada en el art. 24,3 Reglamento Hotelero de Andalucía: "La dispensa deberá compensarse mediante la oferta de servicios complementarios o condiciones adicionales a los que les corresponderían según su grupo y categoría, mediante la utilización de energías renovables o por la incorporación de otras instalaciones y medidas tendentes a la mejora del medio ambiente".

- Respeto al entorno geográfico, natural o arquitectónico en el que se ubica el establecimiento hotelero. Especiales limitaciones ambientales para establecimientos situados junto a espacios naturales protegidos, en el medio rural, en zonas de especial valor paisajístico o histórico-artístico, etc.

- Actuaciones dirigidas a la protección del patrimonio, tales como, la gastronomía tradicional en determinados establecimientos ${ }^{37}$; facilitar a los clientes información turística del entorno geográfico; medidas de protección del entorno natural o rural; rehabilitación de edificios que formen parte del patrimonio histórico-artístico o arquitectónico; etc.

\subsection{La singular utilización del sistema de clasificación hotelera en la política de control de precios}

Por último, debemos destacar, en relación con la finalidad del sistema de clasificación de los establecimientos hoteleros, su utilización, durante largo tiempo, como instrumento de intervención sobre la oferta hotelera y, especialmente, en cuanto se refiere al control de los precios. Precisamente, ya la primera reglamentación de clasificación de establecimientos hoteleros aprobada por Orden de 8 de abril de 1939, sobre la que volveremos más adelante, incluyó entre las competencias que asumía el Ministerio de Gobernación y el Servicio Nacional de Turismo "Fijar las categorías de dichos establecimientos,

\footnotetext{
${ }^{37}$ Hoteles gastronómicos de Andalucía y Galicia, por ejemplo.
} 
previa propuesta, cuando se estime oportuno de la Cámara Hotelera, y los precios de los mismos". Este sistema de intervención sobre los precios ${ }^{38}$, en función de las categorías de los establecimientos, estuvo en vigor hasta que la Orden Ministerial de 15 de septiembre de 1978 implantó su liberalización ${ }^{39}$, estableciendo que:

Todos los alojamientos turísticos, cualquiera que sea su clase y categoría, fijarán sus precios máximos y mínimos sin más obligación que la de notificar los mismos a la Administración Turística.

Por tanto, entre los años 1939 y 1978 la intervención administrativa sobre los precios de los establecimientos hoteleros, tomando como referencia las distintas categorías, fue muy relevante, si bien, el Estado propició una progresiva liberalización ${ }^{40}$ hasta llegar a la precitada Orden de 15 de septiembre de 1978.

${ }^{38}$ La intervención administrativa sobre los precios de los establecimientos de hospedaje data de mediados del siglo XIX, teniendo gran incidencia a partir de las Exposiciones de Barcelona y Sevilla de 1929 y durante el largo periodo del desarrollo del turismo, hasta la liberalización producida, según se indica, en 1978. Exponente de la política de control sobre los precios es la Orden de 28 de marzo de 1966, sobre precios y reservas en la Industria Hotelera, que vino a reforzar la anterior normativa contenida en la Orden de 7 de noviembre de 1962. En la Exposición de Motivos de la Orden se indica lo siguiente: "Con la fidelidad debida a los principios rectores establecidos en aquel texto ordenador (Orden de 7.11.1962): claridad, publicidad, inalterabilidad y juego leal de competencias -dentro de un sistema elástico- de «máximos» y «mínimos» que permiten la adaptación al juego estacional de la demanda, el régimen de precios de la Industria Hotelera, como materia clave y de directa repercusión sobre el turismo, continúa reclamando una atención preferente".

${ }^{39}$ Para BOTE GÓMEZ, V. y MARCHENA GÓMEZ, M., la liberalización responde a los cambios políticos y de política económica del momento: "En el caso de la política turística el instrumento más significativo de esta liberalización son los precios hoteleros. A partir de 1978, esta política turística -tradicionalmente criticada por su exceso de intervencionismo y burocratismo- suprimió definitivamente el sistema de precios máximos y mínimos autorizados en los establecimientos hoteleros, rompiendo así con la obsesión por los precios baratos del periodo anterior", en PEDREÑO MUÑOZ, A. (Dir.), Introducción a la economía del turismo en España, Cívitas, Madrid, 1996, p. 307.

40 En palabras de RODRÍGUEZ PIÑERO, "También aquí la nueva política liberalizadora ha modificado sensiblemente el excesivo intervencionismo anterior. Desde la guerra civil hasta 1962 existió una política de tasación rigurosa de precios, que por su carencia de flexibilidad dio lugar tanto a un estancamiento de la propia actividad hotelera, al no ser rentables las mejoras, como a una conducta muy generalizada de inobservancia más o menos abusiva en la materia. La Orden de 7 de noviembre de 1962 inicia una política liberalizadora mediante un régimen transitorio de liberalización, que prosigue en la Orden de 4 de agosto de 1963 y que estabiliza la reciente Orden de 28 de marzo de 1966”. Op. Cit., p. 214. 
Este proceso de liberalización fue ampliado posteriormente por las Comunidades Autónomas, dejando un mayor margen de actuación a los empresarios en la determinación de los precios de los distintos servicios, como corresponde a un sistema de economía de mercado.

\section{Origen y evolución de la clasificación administrativa de los establecimien- tos hoteleros}

El estudio de la intervención de los poderes públicos sobre determinados aspectos de los hoy denominados alojamientos turísticos, se remonta a prescripciones contenidas en el Derecho Romano, así como, posteriormente, a disposiciones de policía de vigilancia dictadas durante la Edad Media y el Renacimiento ${ }^{41}$. Sin embargo, como antecedentes inmediatos de la ordenación de los establecimientos hoteleros, deben citarse la Real Orden de 27 de noviembre de 1858, que impuso a las casas de huéspedes, de dormir, fondas y hospederías, la licencia previa del ramo de vigilancia; la Real Orden de 17 de marzo de 1909, facultando a los gobernadores civiles, en las capitales de provincias, y a los alcaldes, en las demás poblaciones, para expedir licencias de apertura de establecimientos de hospedaje; y las Reales Órdenes de 11 de diciembre de 1928 y de 29 y 30 de enero de 1929, dictadas con ocasión de la proximidad de las Exposiciones de Barcelona y Sevilla, estableciendo la publicación de la Guía Oficial de alojamientos, con expresión de sus precios mínimos y máximos y la obligación de contar con un Libro Oficial de Reclamaciones.

No obstante, será la Orden de 8 de abril de 1939, la que apruebe la primera reglamentación de establecimientos hoteleros, propiamente dicha ${ }^{42}$. En

${ }^{41}$ Una exposición detallada de esta intervención la encontramos en FERNÁNDEZ ÁLVAREZ, J., Curso de Derecho Administrativo Turístico, Op. Cit., Vol. I., especialmente pp. 40-46. Puede consultarse igualmente la obra de CEBALLOS MARTÍN, M.M., La regulación jurídica de los establecimientos hoteleros, Marcial Pons, Barcelona, 2002, especialmente pp. 38 ss.

${ }^{42}$ La efectiva aplicación práctica de esta disposición dio lugar a una singular disposición ministerial contenida en la Orden de 8 de abril de 1941 conminando a los hoteleros a cumplir en el plazo perentorio de un mes con la normativa aprobada en 1939 a cuyo término se reputarían clandestinos los establecimientos no adaptados. La Exposición de Motivos de esta disposición no deja de resultar sorprendente: "Observándose que son muchos los industriales que no cumplen lo dispuesto en la Orden de 8 de abril de 1939 sobre funcionamiento de la industria hotelera española, lo que supone un perjuicio para los industriales que ajustan su trabajo a normas legales, este Ministerio se ha servido disponer (...)". 
esta disposición se determina la competencia del Ministerio de Gobernación y del Servicio Nacional de Turismo (de él dependiente) para autorizar la apertura de establecimientos hoteleros, fijar las categorías de los mismos, determinar sus precios e inspeccionar los servicios hoteleros. Se procede a clasificar por vez primera los establecimientos hoteleros de la siguiente forma:

\begin{tabular}{|c|c|c|}
\hline Grupo & Modalidad & Categoría \\
\hline \multirow{2}{*}{$\begin{array}{c}\text { A. Establecimientos con } \\
\text { servicio de comedor }\end{array}$} & Hoteles o Paradores & $\begin{array}{c}\text { Lujo, Primera A, Prime- } \\
\text { ra B, Segunda y Tercera }\end{array}$ \\
\cline { 2 - 3 } & $\begin{array}{c}\text { Casas de Huéspedes y } \\
\text { Posadas }\end{array}$ & $\begin{array}{c}\text { Primera, Segunda y } \\
\text { Tercera }\end{array}$ \\
\cline { 2 - 3 } & Única \\
\hline $\begin{array}{c}\text { B. Alojamientos no do- } \\
\text { tados de comedor }\end{array}$ & $\begin{array}{c}\text { Alojamientos no dota- } \\
\text { dos de comedor }\end{array}$ & $\begin{array}{c}\text { Primera, Segunda y } \\
\text { Tercera }\end{array}$ \\
\hline
\end{tabular}

Sin embargo, la reglamentación no estableció criterio alguno para que la Administración pudiera efectuar de forma objetiva y uniforme el otorgamiento de la categoría correspondiente, determinando únicamente que la clasifi-

43 El término "Parador" o "Paradores" empleado inicialmente de forma libre por los establecimientos hoteleros, quedó posteriormente reservado para su utilización por el Estado por Orden de 5 de noviembre de 1940, ratificada posteriormente por Decreto de 4 de abril de 1952. De esta forma se implanta un privilegio a favor del sector público por medio de una prohibición de uso en la denominación legal y en el nombre comercial de los establecimientos hoteleros, que se unía a otras limitaciones impuestas en la misma dirección, como la necesidad de respetar, por parte de la iniciativa hotelera privada, una distancia mínima respecto a los Paradores existentes, conforme determinaba el precitado Decreto (prohibición ésta derogada por Decreto 3087/1962, de 22 de noviembre). La prohibición sobre el término «parador» se mantuvo posteriormente en la Orden de 19 de julio de 1968, de clasificación de establecimientos hoteleros y actualmente aparece expresamente recogida en los Reglamentos de Hoteles de Cantabria (Art. 5); Extremadura (Art. 8); Galicia (Art. 8); Región de Murcia (Art. 8) y La Rioja (Art. 28). Sobre esta cuestión Vid., PALMA FERNÁNDEZ, J.L., "Ordenación jurídica de los Paradores de Turismo", en BLANQUER CRIADO, D., Turismo, Organización administrativa, calidad de servicios y competitividad empresarial, Tirant lo Blanch, Valencia, 1999, especialmente pp. 117-118 y CEBALLOS MARTÍN, M.M. y PÉREZ GUERRA, R., "El régimen jurídico-administrativo de Paradores de Turismo en España", en Papers de Turisme, núm. 26, 1999, pp. 48-61. 
cación se concediera "según la calidad de los servicios que estén en condiciones de prestar al público" (Art. 3). Para resolver esta situación se aprobó la Orden de 14 de junio de 1957, conformando una detallada reglamentación hotelera $^{44}$, que impuso una nueva clasificación, efectuando modificaciones y añadidos sobre la base de la aprobada en 1939, quedando de la siguiente forma:

\begin{tabular}{|c|c|c|}
\hline Grupo & Modalidad & Categoría \\
\hline \multirow{3}{*}{ I. Hoteles y Pensiones } & Hoteles & $\begin{array}{l}\text { Lujo, Primera A, Prime- } \\
\text { ra B, Segunda y Tercera }\end{array}$ \\
\hline & Pensiones & $\begin{array}{c}\text { Lujo, Primera, Segunda } \\
\text { y Tercera }\end{array}$ \\
\hline & $\begin{array}{c}\text { Casas de Huéspedes y } \\
\text { Posadas } \\
\end{array}$ & Única \\
\hline $\begin{array}{l}\text { II. Hoteles en } \\
\text { Balnearios }\end{array}$ & Hoteles en Balnearios & $\begin{array}{l}\text { Lujo, Primera A, Prime- } \\
\text { ra B, Segunda y Tercera }\end{array}$ \\
\hline \multirow{2}{*}{$\begin{array}{l}\text { III. Alojamientos no } \\
\text { dotados de comedor }\end{array}$} & Hoteles & $\begin{array}{l}\text { Lujo, Primera A, Prime- } \\
\text { ra B, Segunda y Tercera }\end{array}$ \\
\hline & Pensiones & $\begin{array}{c}\text { Lujo, Primera, Segunda } \\
\text { y Tercera }\end{array}$ \\
\hline $\begin{array}{l}\text { IV. Alojamientos even- } \\
\text { tuales en casas } \\
\text { particulares }\end{array}$ & - & - \\
\hline
\end{tabular}

Sin embargo, como se ha indicado, la novedad principal que aportó la nueva regulación hotelera fue la determinación de los requisitos que habrían de cumplir los establecimientos para poder acceder a una u otra clasificación. Para ello el Reglamento dedicó un artículo a cada una de las categorías existentes, además de prescripciones que afectaban al conjunto de establecimientos, con independencia de su categoría.

${ }^{44}$ La Orden estaba formada por 67 artículos, distribuidos en tres capítulos en los que se regulaba, las facultades administrativas y autorización de apertura (Capítulo I), la clasificación de los establecimientos hoteleros y normas que han de cumplirse en su explotación (Capítulo II) y el Libro oficial de reclamaciones, listas de precios, sanciones y recursos (Capítulo III). 
La normativa reseñada estuvo vigente hasta los primeros años del denominado boom del turismo, quedando derogada por el Decreto 231/1965, que aprobó el Estatuto Ordenador de Empresas y Actividades Turísticas Privadas, si bien se mantuvo de forma transitoria su aplicación hasta la aprobación de la nueva reglamentación por Orden de 19 de julio de $1968^{45}$.

La Orden de 19 de julio de 1968 provocó una modificación sustancial del sistema de clasificación hotelera, incorporando la conocida fórmula de clasificación "por estrellas" y superando la reglamentación anterior en su carácter detallista (con un total de 86 artículos). La clasificación establecida preveía la existencia de cuatro grupos (Hoteles; Hostales y Pensiones; Fondas; Hoteles-Apartamentos), si bien dentro de las especialidades esta clasificación se veía duplicada por establecimientos de las mismas categorías pero carentes de servicio de comedor (Hoteles-Residencias; Hostales-Residencias; Casas de Huéspedes y Residencias-Apartamentos), además de la especialidad de Motel, con tres categorías. La clasificación puede plasmarse de la siguiente forma:

\begin{tabular}{|c|c|c|}
\hline Grupo & Modalidad & Categoría \\
\hline \multirow{2}{*}{ I. Hoteles } & Hoteles & $\begin{array}{c}\text { Cinco, cuatro, tres, dos } \\
\text { y una estrellas. }\end{array}$ \\
\hline \multirow{2}{*}{ II. Hostales y Pensiones } & Hostales & Tres, dos y una estrellas \\
\cline { 2 - 3 } & Pensiones & Tres, dos y una estrellas \\
\hline III. Fondas & - & - \\
\hline $\begin{array}{c}\text { IV. Hoteles- } \\
\text { Apartamentos }\end{array}$ & Hoteles-Apartamentos & $\begin{array}{c}\text { Cuatro, tres, dos y una } \\
\text { estrellas }\end{array}$ \\
\hline
\end{tabular}

45 Vid. Disposiciones Finales del Decreto 231/1965. Por su parte la Orden de 1968 fue modificada por Orden de 16 de febrero de 1970 en relación con la utilización de los calificativos de «lujo» y «gran lujo». Las ulteriores modificaciones efectuadas por Orden de 14 de febrero de 1971 y de 19 de junio de 1974, no afectaron a la clasificación, al tener por objeto la regulación de aspectos puntuales del servicio de comedor. 
Establecimientos hoteleros especializados

\begin{tabular}{|c|c|c|}
\hline Grupo & Modalidad & Categoría \\
\hline \multirow{4}{*}{ Sin servicio de comedor } & Hoteles-Residencias & $\begin{array}{c}\text { Cinco, cuatro, tres, dos } \\
\text { y una estrellas }\end{array}$ \\
\hline & Hostales-Residencias & Tres, dos y una estrellas \\
\hline & Casas de Huéspedes & - \\
\hline & $\begin{array}{l}\text { Residencias- } \\
\text { Apartamentos }\end{array}$ & $\begin{array}{c}\text { Cuatro, tres, dos y una } \\
\text { estrellas }\end{array}$ \\
\hline Moteles & Moteles & Tres, dos y una estrellas \\
\hline $\begin{array}{l}\text { Playa, alta montaña, si- } \\
\text { tuados en estaciones } \\
\text { termales }\end{array}$ & $\begin{array}{l}\text { Hoteles, Hoteles-Apar- } \\
\text { tamentos, Hoteles-Resi- } \\
\text { dencias y Residencias- } \\
\text { Apartamentos }\end{array}$ & $\begin{array}{l}\text { Las correspondientes a } \\
\text { cada modalidad }\end{array}$ \\
\hline
\end{tabular}

Posteriormente, por Real Decreto 3093/1982, de 15 de octubre, se aprobó un nuevo reglamento de ordenación y clasificación de los establecimientos hoteleros. Esta disposición impuso dos modificaciones sustanciales, la primera, una simplificación significativa de las modalidades y categorías de los establecimientos hoteleros, clasificándolos en dos grupos, el grupo I para los hoteles (con hoteles, hoteles-apartamentos y moteles de una a cinco estrellas) y el grupo II para Fondas, con categoría única. La segunda transformación se refería a los criterios de clasificación, al introducir, junto a un conjunto de requisitos técnicos mínimos por categoría, un sistema de valoración del nivel de calidad de los servicios ofrecidos. Sin embargo, este Decreto encontró una gran oposición dentro del sector hotelero y, al coincidir con el cambio de Gobierno, se logró, primero un aplazamiento a su entrada en vigor ${ }^{46} \mathrm{y}$, a continuación, la redacción y aprobación de una nueva disposición, por lo que la reglamentación contenida en el Real Decreto 3093/1982, no llegó a aplicarse.

${ }^{46}$ El Real Decreto 3692/1982, de 15 de diciembre, aplazó la entrada en vigor del Real Decreto 3093/1982 en seis meses. Días antes de finalizar dicho plazo se aprobó el nuevo Decreto. 
La última reglamentación hotelera aprobada por el Estado se inserta en el Real Decreto 1634/1983, de 15 de junio. Con esta disposición se procedió a derogar el efímero Real Decreto 3093/1982, suprimiendo la fórmula mixta adoptada por aquél, y se procuró implantar una nueva regulación que pretendía alcanzar una mínima uniformidad en la ordenación hotelera de todo el territorio del Estado. En la propia Exposición de Motivos de la norma se incluye como principio inspirador, precisamente, "asegurar la necesaria homogeneidad en el Estado en materia evidentemente precisa de un marco común de referencia que sirva a la clarificación de la oferta hotelera". Este objetivo no se cumplió a largo plazo puesto que las Comunidades Autónomas hicieron valer su capacidad de ordenación del sector, contando para ello con el valioso apoyo del Tribunal Constitucional en su Sentencia 125/1984, de 20 de diciembre, dictada en oposición al Real Decreto 2288/1983, de 27 de julio, mediante el cual el Estado pretendía otorgar a los establecimientos hoteleros la distinción especial de «recomendado por su calidad», afirmando el Alto Tribunal que:

La distinción especial «Recomendado por su calidad» que se crea en el Real Decreto 2288/1983 para otorgarla a establecimientos hoteleros implica, tal como está concebida, una clasificación paralela de aquellos establecimientos. Así se desprende del artículo $4^{\circ}$, en donde se establece que la calidad de los servicios a premiar se valorará «con independencia de la categoría en que se hallen clasificados los establecimientos». Nadie discute en este conflicto que es competencia comunitaria la clasificación de los establecimientos hoteleros. Ahora bien, al valorarse su calidad, como dispone el artículo 4, con arreglo a unos baremos relativos a su capacidad, al número de empleados y su cualificación, a los servicios e instalaciones adicionales y a la calidad de los elementos materiales, que son en sustancia los mismos criterios que se utilizan para la ordenación en categorías de los establecimientos hoteleros por las Comunidades, es claro que la aplicación del Real Decreto impugnado crearía la apariencia de una doble clasificación hotelera y, en cuanto tal, significa una invasión de la competencia comunitaria de ordenación de este importante sector de la actividad turística.

La disposición aprobada por el Estado sí logra, en cambio, una notable simplificación en la clasificación hotelera, acorde con la pretendida en el derogado Real Decreto 3093/1982, quedando considerablemente reducida con respecto a la precedente de 1968 : 


\begin{tabular}{|c|c|c|}
\hline Grupo & Modalidad & Categoría \\
\hline \multirow{4}{*}{ I. Hoteles } & Hotel & $1-5$ estrellas \\
\cline { 2 - 3 } & Hotel-Apartamento & $1-5$ estrellas \\
\cline { 2 - 3 } & Motel & Única \\
\hline II. Pensiones & Pensión & $1-2$ estrellas \\
\hline
\end{tabular}

Esta clasificación estatal de los establecimientos hoteleros, que por razones de competencia no se pudo imponer a las Comunidades Autónomas, fue parcialmente seguida por algunas reglamentaciones autonómicas, pero progresivamente fueron apareciendo nuevas disposiciones legales (particularmente, las Leyes de Turismo) y reglamentarias, que optaron por clasificar a los establecimientos hoteleros sin sujeción al modelo estatal, aunque no dejen de existir, como se verá infra, elementos comunes y similitudes entre todas ellas.

\section{Clasificación de los establecimientos hoteleros en grupos, clases, catego- rías modalidades y especialidades}

Como se ha visto anteriormente, una de las funciones que la Administración pública asume en la ordenación del sector hotelero se corresponde con la clasificación de los establecimientos que lo integran. Resulta, a nuestro juicio, uno de los instrumentos de mayor penetración de la acción pública de ordenación de un sector económico privado, puesto que abarca muy intensas facultades de actuación. Éstas se pueden agrupar en facultades previas a la concesión de la clasificación (incluyendo dicho otorgamiento) y facultades posteriores a la clasificación, que derivan de dicho acto de la Administración. Entre las facultades administrativas previas al acto de otorgamiento de clasificación, destacaremos las siguientes: a) La determinación de la clasificación impuesta preceptivamente a los establecimientos (en grupos, modalidades, categorías, etc.); b) Establecimiento del sistema y criterios de clasificación (cerrada, por puntuación, por valoración, etc.); c) Regulación del distintivo acreditativo de cada categoría, modalidad y especialidad, en su caso; d) La fijación de los requisitos que han de observarse para acceder a cada categoría mediante la aprobación de disposiciones reglamentarias de carácter técnico; e) Regulación del procedimiento para solicitar y obtener de la Administración la clasificación que deba corresponder a cada establecimiento; f) Delimitación de los supuestos y del procedimiento para la obtención de la dispensa en el cumplimiento de algún requisito correspondiente a la categoría solicitada a la Admi- 
nistración; g) Concesión de la clasificación que deba ostentar el establecimiento tras la tramitación del procedimiento correspondiente, y, en su caso, de la dispensa solicitada.

A estas facultades directamente vinculadas con la implantación de un sistema administrativo de clasificación de establecimientos hoteleros habremos de añadir aquellas otras que se activan una vez que el establecimiento ha obtenido una determinada clasificación y se encuentra en funcionamiento. Resaltaremos entre las funciones más relevantes, las siguientes: a) La función inspectora; b) La facultad de reclasificación de oficio y la revocación de la autorización por incumplimiento de las condiciones esenciales que justificaron su otorgamiento; c) La reclasificación a instancia de parte y las autorizaciones para efectuar reformas sustanciales en el establecimiento; d) El ejercicio de la potestad sancionadora; e) La exigencia de adaptación a los cambios que se introduzcan en la clasificación vigente en cada momento (fruto del ejercicio de la potestad reglamentaria).

Unas facultades y otras son consecuencia de la potestad de ordenación, que el ordenamiento otorga a la Administración pública en desarrollo de la Ley de Turismo, y encuentran su razón de ser en la implantación de un modelo jurídico-público de clasificación de los establecimientos hoteleros, frente a modelos iusprivatistas vigentes en otros países. Por ello, creemos conveniente analizar a continuación los tipos de clasificación vigentes actualmente en España, como epicentro del conjunto de facultades administrativas enunciadas.

Hasta que las Comunidades Autónomas aprueban sus respectivos reglamentos de ordenación y clasificación hotelera, existe una clasificación única, regulada, como se ha indicado supra, por el Real Decreto 1634/1983, de 15 de junio. El modelo de clasificación que implantaba esta disposición a nivel nacional, era el siguiente:

\begin{tabular}{|c|c|c|}
\hline Grupo & Modalidad & Categoría \\
\hline \multirow{3}{*}{ I. Hoteles } & Hotel & $1-5$ estrellas \\
\cline { 2 - 3 } & Hotel-Apartamento & $1-5$ estrellas \\
\cline { 2 - 3 } & Motel & $\begin{array}{c}\text { Única } \\
\text { (Requisitos hotel 3 estrellas) }\end{array}$ \\
\hline II. Pensiones & Pensión & $1-2$ estrellas \\
\hline
\end{tabular}


Esta clasificación fue sustituida paulatinamente por la correspondiente a cada Comunidad Autónoma y, aunque en principio se mantuvo el esquema planteado por la Administración Central, con algunas modificaciones que no resultaron especialmente significativas, con el tiempo han aparecido diferentes modelos, e incluso variaciones dentro de los modelos existentes, que impiden tratar de forma uniforme la clasificación vigente en la actualidad. Analizando la compleja normativa dictada por las Comunidades Autónomas, podemos destacar la existencia, en el ámbito autonómico, de dos modelos generales y cuatro específicos, manteniéndose además el modelo estatal vigente en la Comunidad Autónoma de las Islas Baleares ${ }^{47}$, así como, en las Ciudades Autónomas de Ceuta y Melilla. Examinemos brevemente los modelos implantados por las Comunidades Autónomas.

\subsection{Modelo general de clasificación en dos grupos}

Mantiene un esquema muy similar al aprobado por el Estado, si bien desaparece como modalidad propia el motel, que pasa a considerarse una especialización.

\begin{tabular}{|c|c|c|}
\hline Grupo & Modalidad & Categoría \\
\hline \multirow{2}{*}{ I. Hoteles } & Hotel & $1-5$ estrellas \\
\cline { 2 - 3 } & Hotel-Apartamento & $1-5$ estrellas \\
\hline II. Pensiones & Pensión & $1-2$ estrellas \\
\hline
\end{tabular}

La ventaja principal que presenta este primer modelo de clasificación es su simplicidad, al reducir a tres las modalidades y a siete los niveles de categoría ${ }^{48}$. Este modelo es el vigente, con pequeñas variantes, en las Comunidades

${ }^{47}$ En Baleares se aplica la normativa estatal de 1983, con su correspondiente clasificación, si bien la Ley 2/1999, de 24 de marzo, General de Turismo, en su art. 20 limita la clasificación a cinco categorías distribuidas en dos grupos, hoteles y hoteles-apartamentos. Implica la desaparición de las categorías inferiores de hostales y pensiones, con objeto de incrementar la calidad de las instalaciones hoteleras. Con respecto a los establecimientos clasificados como hostales, hostales-residencias, pensiones, fondas y casas de huéspedes, la Ley establece que "mantendrán su categoría como alojamientos turísticos y deberán superar los planes de modernización que se creen” (D.T. $3^{\underline{a}}$ ).

${ }^{48}$ Cinco del grupo I más dos del grupo II, organizados de forma consecutiva en cuanto a los requisitos de instalaciones y servicios. 
Autónomas de Canarias ${ }^{49}$, Cataluña ${ }^{50}$, País Vasco, Principado de Asturias y Cantabria. En esta última, se introduce como variación en el grupo I la modalidad de motel, con categorías de dos y tres estrellas ${ }^{51}$. También podemos incluir en este modelo el sistema establecido en la Región de Murcia, aunque plantea como diferenciación la división del grupo I en dos, manteniendo en lo demás el modelo original, es decir, grupo I hoteles (1-5 estrellas); grupo II hotel-apartamento (1-5 estrellas) y grupo III pensiones (1-2 estrellas).

\subsection{Modelo general de clasificación en tres grupos}

El segundo modelo de clasificación se obtiene por la reintroducción de los hostales, que desaparecieron de la clasificación estatal de 1983. Supone, además, incrementar hasta ocho el número de categorías ${ }^{52}$.

\begin{tabular}{|c|c|c|}
\hline Grupo & Modalidad & Categoría \\
\hline \multirow{2}{*}{ I. Hoteles } & Hotel & $1-5$ estrellas \\
\cline { 2 - 3 } & Hotel-Apartamento & $1-5$ estrellas \\
\hline II. Hostales & Hostal & $1-2$ estrellas \\
\hline III. Pensiones & Pensión & única \\
\hline
\end{tabular}

Esta configuración se mantiene en las Comunidades Autónomas de Extremadura, Castilla y León, La Rioja y Comunidad de Valencia, si bien con ciertas variantes en los tres últimos casos. En Castilla y León se incorpora el

${ }^{49}$ En Canarias existen realmente seis categorías, al incorporar la normativa como tal los hoteles cinco estrellas-lujo.

${ }^{50}$ En Cataluña es preciso destacar la modificación impuesta por el art. 41 de la Ley de Turismo, aún no desarrollado reglamentariamente en este punto, al prever la existencia de dos grupos, hoteles y hostales o pensiones, incluyendo en el grupo primero los hoteles, hoteles-apartamentos y balnearios.

51 En su origen la Reglamentación de Cantabria aprobada por Decreto 50/1989, de 5 de junio, incluía un tercer grupo para las Posadas en Casas de Labranza, con las modalidades de Posada y Vivienda Vacacional. Estos establecimientos han desaparecido al regularse por Decreto 31/1997, de 23 de abril, los alojamientos y actividades turísticas en el medio rural, con una ordenación y clasificación diferenciada de la propiamente hotelera.

52 Cinco correspondientes al grupo hoteles, dos al grupo de hostales y uno al de pensiones. 
motel como modalidad propia del grupo I, clasificado igualmente en cinco categorías. En La Rioja, en cambio, se mantienen los tres grupos (Hoteles, hostales y pensiones) sin modalidad y se incluye al hotel-apartamento dentro de la especialización ${ }^{53}$ y en la Comunidad de Valencia se incluyen modalidades específicas de alojamiento sin servicio de comidas (Hoteles-residencias; hoteles-apartamentos residencias y hostales-residencias), siguiendo, en parte, el diseño de 1968.

El esquema planteado en este segundo modelo general es seguido también por otras Comunidades Autónomas, aunque con variaciones relacionadas con las categorías que se otorgan a hostales y pensiones. La fórmula más parecida es la implantada en Aragón, que supone una simplificación adicional al mantener a hostales y pensiones en categoría única, por lo que se mantiene, de esta forma, la existencia de sólo siete niveles de categoría, igual que en el modelo anterior ${ }^{54}$.

Finalmente, debe ser incluida en este grupo la Comunidad Autónoma de Castilla-La Mancha, que conserva la división en tres grupos, pero con dos categorías de hostales y dos de pensiones, además de introducir la modalidad de motel en el grupo I, con categoría única. Supone, por tanto, la existencia en esta Comunidad Autónoma de 9 niveles de categoría ${ }^{55}$.

\subsection{Modelos específicos de clasificación}

En algunas Comunidades Autónomas se han creado tipologías concretas de clasificación que, aunque mantengan algunas notas comunes con los modelos genéricos comentados, imponen novedades significativas. Tal es el caso de las Comunidades Autónomas de Andalucía, Galicia, Comunidad de Madrid y Comunidad Foral de Navarra.

\footnotetext{
53 Prevé, además dos regímenes de explotación, uno general (con comedor) y otro específico de alojamiento.

${ }^{54}$ Cinco para hoteles, una para hostales y una para pensiones.

55 Cinco para el grupo I, dos para el grupo II y dos para el grupo III.
} 


\section{Modelo de Andalucía:}

El modelo andaluz parte de la subdivisión en cuatro grupos, correspondientes a hotel, hostal, pensión y hotel-apartamento, considerando como modalidades las correspondientes a playa, ciudad, rural y carretera. Pese a modificar el esquema general, el Decreto 47/2004 implanta un total de ocho niveles de categoría (cinco de hoteles, 2 de hostales y uno de pensiones).

\begin{tabular}{|c|c|c|}
\hline Grupo & Modalidad & Categoría \\
\hline I. Hoteles & Playa & $1-5$ estrellas \\
\hline II. Hostales & Ciudad & $1-2$ estrellas \\
\cline { 1 - 1 } III. Pensiones & $\begin{array}{c}\text { Rural } \\
\text { Carretera }\end{array}$ & única \\
\cline { 1 - 1 } IV. Hoteles-Apartamentos & & \\
\hline
\end{tabular}

\section{Modelo Gallego:}

La Comunidad de Galicia se ha decantado por una tipología de clasificación simplificada, con únicamente dos grupos, de hoteles y pensiones, y un total de ocho niveles de clasificación. No incorpora modalidades e incluye en la especialización tanto a hoteles-apartamentos como a moteles.

\begin{tabular}{|c|c|}
\hline Grupo & Categoría \\
\hline I. Hoteles & $1-5$ estrellas \\
\hline II. Pensiones & $1-3$ estrellas \\
\hline
\end{tabular}

\section{Modelo de la Comunidad de Madrid:}

La Comunidad de Madrid utiliza un sistema complejo, por cuanto mantiene las denominaciones de pensiones y hostales con tres categorías, además de las casas de huéspedes, denominación no utilizada por los restantes reglamentos autonómicos ${ }^{56}$. Las pensiones y hostales se diferencian entre sí por su tamaño y capacidad, puesto que los hostales son pensiones con un mínimo de 10 habitaciones y 20 plazas. Las casas de huéspedes son pensiones que no alcanzan los requisitos mínimos para clasificarse en estrellas. Le corresponden, por tanto, un total de nueve niveles de clasificación ${ }^{57}$.

\footnotetext{
56 Vid. Art. 26 LT Comunidad de Madrid.

57 Cinco de hoteles, tres de pensiones y hostales y uno de casas de huéspedes.
} 


\begin{tabular}{|c|c|}
\hline Grupo & Categoría \\
\hline I. Hoteles & $1-5$ estrellas \\
\hline II. Pensiones y Hostales & $1-3$ estrellas \\
\hline III. Casas de Huéspedes & única \\
\hline
\end{tabular}

\section{Modelo de la Comunidad Foral de Navarra:}

La Comunidad Foral de Navarra presenta, en la reglamentación de más reciente aprobación, un cuadro de clasificación con cinco grupos, por la incorporación de los hoteles rurales y hostales rurales. Al margen de esta inclusión, sigue el modelo general de clasificación en tres grupos, aunque intercambiando las categorías de hostales y pensiones. Le corresponden, por tanto, un total de ocho niveles de categoría.

\begin{tabular}{|c|c|}
\hline Grupo & Categoría \\
\hline I. Hoteles & $1-5$ estrellas \\
\hline II. Hoteles Rurales & $1-5$ estrellas \\
\hline III. Hoteles-Apartamentos & $1-5$ estrellas \\
\hline IV. Hostales & General y Rural (única) \\
\hline V. Pensiones & $1-2$ estrellas \\
\hline
\end{tabular}

En conclusión, esta diversidad de modelos, muchos de ellos contemplando pequeñas variaciones sobre otros anteriores, plantea la necesidad de alcanzar una mínima uniformidad en materia de clasificación hotelera, de manera que la promoción e información, especialmente en el extranjero, permita la mayor homogeneidad posible, en beneficio del usuario turístico ${ }^{58}$. Sin embargo, esta cuestión excede del objetivo del presente trabajo.

\section{Características del acto administrativo de autorización-clasificación de los establecimientos hoteleros}

Los establecimientos hoteleros, con independencia de su clase y categoría, están sometidos a la previa obtención de una autorización considerada es-

58 En ocasiones, esta uniformidad se plantea a nivel internacional. Vid. PÉREZ MORIONES, A., El contrato de gestión hotelera, Tirant lo Blanch, Valencia, 1998, p. 194. 
pecial o específica, impuesta por la legislación sectorial turística, que se añade a las restantes autorizaciones o licencias que el ordenamiento impone con carácter general a las actividades empresariales (licencia de obras, en su caso; licencia de apertura; licencia de primera ocupación, etc. $)^{59}$, y que otorga el órgano correspondiente de la Consejería competente en materia de turismo. Así, a tenor de lo dispuesto en los dos primeros apartados del art. 25 de la LT del Principado de Asturias:

1. Las empresas turísticas, con anterioridad al inicio de sus actividades, deberán solicitar de la Administración turística competente la correspondiente autorización para el ejercicio de las mismas y la clasificación, en su caso, de los establecimientos, con arreglo al procedimiento reglamentariamente establecido. Dicha autorización es independiente de las que corresponda otorgar a otros órganos, en virtud de sus respectivas competencias. En todo caso, para la concesión de la autorización turística se requerirá la previa licencia municipal de apertura.

2. Igualmente, las empresas turísticas deberán instar la correspondiente autorización para realizar cualquier modificación o reforma sustancial que afecte a las condiciones en las que se otorgaron la autorización y clasificación inicial, así como en los casos en los que se produzcan cambios en el uso turístico o en la titularidad del establecimiento.

Esta autorización se configura, pues, como un instrumento administrativo de limitación dirigido a la ordenación y vigilancia de los establecimientos de alojamiento hotelero. Las características básicas que presenta este tipo de autorización lo tipifican como un acto administrativo esencialmente reglado, de funcionamiento, real y de carácter operativo.

\footnotetext{
${ }^{59}$ Esta concurrencia de autorizaciones, y la problemática que encierra, ha propiciado la intervención jurisprudencial, por ejemplo, en STS de 20 de enero de 1999 (AR. 15); STS de 29 de julio de 1992 (AR. 6594); STS de 3 de abril de 1990 (AR. 3414) y STS de 18 de junio de 1980 (AR. 3221), entre otras. En sus pronunciamientos el Tribunal Supremo suele incidir en la confusión que en ocasiones se produce en los titulares de los establecimientos turísticos entre la licencia municipal de apertura y la autorización de apertura y clasificación que otorga la Administración autonómica. La concesión de una u otra no exime la obligación de contar con ambas. Sobre la concurrencia de licencias en los establecimientos turísticos, Vid., GARCÍA RUBIO, F., "Licencias y establecimientos turísticos", en MELGOSA, F.J., Derecho y Turismo, Universidad de Salamanca, 2004, pp. 179-194.
} 


\subsection{Autorización esencialmente reglada}

En primer lugar, debemos considerar que nos encontramos ante un acto esencialmente reglado, por cuanto la labor que Administración otorgante ha de realizar es de mera comprobación del cumplimiento de los requisitos establecidos por vía normativa, sin que, en principio, se le conceda la facultad de realizar ningún tipo de valoración subjetiva o de oportunidad ${ }^{60}$. A la Administración corresponde comprobar el cumplimiento de los requisitos que la normativa vigente impone para la clase y categoría solicitada por el establecimiento, otorgándola en caso de que se cumplan dichas condiciones y denegándola en caso contrario $^{61}$. La Administración no efectúa una valoración subjetiva del proyecto presentado, ni está capacitada para realizar un juicio de oportunidad en función, por ejemplo, de la oferta turística existente en una determinada zona o de la concentración de la oferta en un segmento de calidad determinado.

Pero este carácter esencialmente reglado de la autorización hotelera no puede preconizarse en todo tiempo. Así, las primeras disposiciones reglamentarias en la materia impusieron, en cambio, un tipo de autorización que debemos considerar como discrecional. En efecto, la Orden de 8 de abril de 1939, primera norma que impuso, como hemos indicado supra, la clasificación de los hoteles por categorías, estableció en su art. 2, tras regular el procedimiento de solicitud, que "El Jefe del Servicio Nacional de Turismo resolverá, teniendo en cuenta la capacidad hotelera de la población y sus posibilidades turísticas, y fijará, si procede, la categoría del establecimiento hotelero (...)" ${ }^{\prime 62}$. Del mis-

${ }^{60}$ Vid. BLANQUER CRIADO, D., Derecho del Turismo, Tirant lo Blanch, Valencia, 1999, pp. 373374; RIVERO YSERN, J.L., "Notas sobre la Ley 12/1999, de ordenación del turismo de Andalucía”, op. cit., p. 207; SANZ SALLA, C.O., en "Los sujetos del turismo: los establecimientos hoteleros y las empresas de alojamiento turístico de carácter no hotelero", en GARCÍA MACHO, R., y RECALDE CASTELLS, A. (Dir.), Lecciones de Derecho del Turismo, Tirant lo Blanch, Valencia, 2000, p. 88; PÉREZ GUERRA, R., "La intervención administrativa en la clasificación de los establecimientos hoteleros: estudio comparativo en el Derecho turístico español", Documentación Administrativa, núm. 259-260, 2001, pp. 322-323.

${ }^{61}$ Para VILLAR ESCURRA, J.L., este tipo de autorizaciones no requiere más que "un mero contraste con los requisitos establecidos en la norma debiendo ser expedida si el particular acredita su cumplimiento", en Derecho Administrativo Especial, Cívitas, Madrid, 1999, p. 84. GARCÍA RUBIO, F., por su parte, fundamenta su carácter reglado con estas palabras: "Puesto que todas y cada una de las determinaciones a la hora de apreciar el proyecto y su clasificación son regladas, esto es, predeterminadas por una norma", en "Licencias y establecimientos turísticos", Op. cit., p. 191.

${ }^{62}$ La discrecionalidad del acto de concesión de la autorización y clasificación se acentúa por el hecho de que la reglamentación no preveía los requisitos que debían cumplirse en función de 
mo tenor será la siguiente reglamentación aprobada por Decreto de 14 de junio de 1957, en cuyo art. 3 y con referencia al Director General de Turismo expresa que "resolverá teniendo en cuenta las circunstancias que concurran, la capacidad hotelera de la población y sus posibilidades turísticas, fijando, caso de otorgar el permiso, la categoría del establecimiento hotelero". Sólo con la entrada en vigor de la Orden de 19 de julio de 1968, sobre clasificación de los establecimientos hoteleros, la autorización hotelera se convierte en un acto reglado, fundamentado en el cumplimiento de condiciones generales y condiciones particulares de la categoría correspondiente (Arts. 15-27).

En la actualidad el otorgamiento de la autorización y clasificación se hace depender únicamente del cumplimiento de los requisitos técnicos que la normativa impone para cada categoría. Podemos considerar, a modo de ejemplo, lo que determina el art. 16,2 de la LT del País Vasco:

A los efectos de la clasificación de los hoteles en la categoría a que se refiere el apartado anterior se valorará objetivamente la oferta de instalaciones y servicios en la forma que reglamentariamente se determine. En todo caso, se considerará: la capacidad receptiva; las circunstancias que concurran en el edificio en que esté instalado el establecimiento y situación del mismo, las condiciones y equipamiento de las habitaciones y de las instalaciones de uso común para los clientes; los servicios complementarios, el número de personal en función de su estructura receptiva; y las condiciones sanitarias y de seguridad.

La autorización para el ejercicio de la actividad hotelera es, además, preceptiva, destacando las Leyes de Turismo la obligación que tienen las empresas de obtener de la Administración turística dicha habilitación, puesto que el ejercicio de la actividad sin el correspondiente permiso convierte a la actividad en «clandestina»y, por tanto, perseguible por la Administración ${ }^{63}$. Ambas cuestiones son destacadas en la LT Andalucía (Art. 35) ${ }^{64}$ :

cada categoría, otorgándose ésta "según la calidad de los servicios que estén en condiciones de prestar al público”. A esta situación vino a poner remedio la reglamentación aprobada en 1957.

${ }^{63}$ Existen algunos pronunciamientos judiciales en los que se destaca el carácter clandestino de los establecimientos hoteleros que carecen de la autorización y clasificación que otorga la Administración turística. Vid., a modo de ejemplo, STS de 20 de enero de 1999 (AR. 15).

${ }^{64}$ Téngase en cuenta que el acto de otorgamiento de la autorización y clasificación conlleva, normalmente de oficio, la inscripción del establecimiento autorizado (con su correspondiente categoría), en el Registro de Turismo de la Comunidad Autónoma. La normativa turística andaluza se centra en la regulación de la inscripción registral de tal forma que a través de ella la Administración autonómica procede a otorgar la autorización y clasificación que corresponda. 
1. Será obligatoria la inscripción registral de todos los sujetos y establecimientos turísticos a que se refiere el apartado segundo del artículo anterior, aunque no concurra en aquéllos la condición de empresarios o la prestación de los servicios turísticos no se realice en establecimientos permanentemente abiertos al público.

2. La inscripción en el Registro de Turismo de Andalucía será requisito indispensable para el inicio de la prestación de los servicios turísticos. Igualmente, será requisito imprescindible para poder acceder a las ayudas y subvenciones que conceda la Consejería competente en materia turística.

3. La falta de inscripción registral de los sujetos y establecimientos a que se refiere el apartado primero será suficiente para la calificación como clandestina de la prestación del servicio turístico de que se trate.

El carácter reglado de la autorización se ve reforzado hasta el punto de que en dos disposiciones legales se configura su concesión como un derecho de la empresa turística. Por una parte, la Ley de Turismo de Andalucía que incluye entre los derechos del empresario turístico el de "obtener de la Administración turística, en los supuestos establecidos en la presente Ley, las autorizaciones y clasificaciones preceptivas para el ejercicio de su actividad". En el mismo sentido, el art. 33,c) de la Ley de Turismo de Navarra incorpora el "derecho a obtener de la Administración Turística, en los supuestos establecidos por esta Ley Foral, la inscripción que sea precisa para el desarrollo de sus actividades o prestación de sus servicios". Lógicamente este derecho no se materializa hasta tanto la Administración compruebe que el establecimiento para el que se solicita la autorización (y clasificación) cumple las condiciones técnicas impuestas por la normativa vigente. A sensu contrario implica la necesidad de motivar, por parte de la Administración, la denegación de la autorización solicitada o el otorgamiento de una clasificación inferior a la instada por el solicitante, a tenor de lo dispuesto en el art. 54 de la Ley 30/1992. Con esta configuración podemos afirmar que en la autorización y clasificación de los establecimientos hoteleros existe un derecho preexistente, reafirmando, por tanto, el carácter declarativo del acto de otorgamiento.

Sin embargo, el carácter reglado de la autorización se encuentra «matizado» por la facultad que detenta la Administración en una doble dirección. Por una parte, la capacidad para el otorgamiento «sustancialmente discrecional» de dispensa de requisitos, asunto que, por su relevancia en relación con el objeto principal de este trabajo, se abordará de forma independiente. Por otra, por la posibilidad de que la Administración autonómica, haciendo uso de la potestad incorporada a las Leyes de Turismo, pueda restringir, e incluso 
cancelar el otorgamiento de nuevas autorizaciones en una determinada zona o limitar la categoría a la que se puede aspirar en dichas áreas. Esta potestad queda necesariamente vinculada, conforme a la Ley, a la previa declaración de zona turística saturada o similar. Se trata de poner en funcionamiento un mecanismo de ordenación turística que las Leyes de Turismo prevén en su articulado con denominaciones diversas ${ }^{65}$, dirigido a limitar el otorgamiento de autorizaciones en aquellas zonas del territorio cuyo excesivo y desordenado desarrollo turístico haga aconsejable un control especialmente intenso en la concesión de nuevas autorizaciones. Así, conforme determina el art. 19 LT del Principado de Asturias:

1. El Consejo de Gobierno del Principado de Asturias, a propuesta de las Consejerías competentes en materia de turismo y ordenación del territorio o del Concejo o Concejos afectados, podrá, con carácter excepcional, declarar, mediante Decreto, zonas turísticas saturadas, previo dictamen preceptivo del Consejo Consultivo de Turismo y sobre la base de estudios técnicos elaborados por las Direcciones Generales competentes en materia de turismo y de ordenación del territorio y, en su caso, de medioambiente del Principado de Asturias, que pongan de manifiesto la necesidad y el interés general de la declaración. Cuando la propuesta no proceda del Concejo o Concejos afectados, éstos habrán de ser en todo caso oídos. 2. Podrá declararse zona turística saturada aquella que, circunscrita a un Concejo o a parte o partes del mismo, o comprensiva de más de un Concejo o partes de varios Concejos, requiera de manera indispensable limitar el incremento de su capacidad turística, por concurrir alguna de las circunstancias siguientes: a) Por sobrepasar el límite de oferta turística máximo que, teniendo en cuenta el número de plazas turísticas por habitante o densidad de población, reglamentariamente se determine. b) Por registrar una demanda que, por su número o tipo de actividad concernida, genere situaciones incompatibles con la legislación medioambiental.

3. La declaración de zona turística saturada implicará la suspensión del otorgamiento de nuevas autorizaciones o permisos para ejercer actividades turísticas de las definidas en el artículo 3 de la presente Ley y por cualquiera de los sujetos referidos en el artículo 24 de la misma, y se mantendrá únicamente hasta tanto no desaparezcan las circunstancias que hayan motivado la declaración.

${ }^{65}$ Puede utilizarse la denominación Zona Turística Saturada (Art. 19 LT Aragón; art. 37 LT Cantabria; art. 14 LT Cataluña; art. 19 LT Principado de Asturias), Área Turística Saturada (Art. 40 LT Comunidad de Madrid; Art. 39 LT Navarra) o Espacio Turístico Saturado (Art. 48 LT Castilla y León). 
Sin embargo, la existencia de limitaciones para acceder a nuevas autorizaciones o a autorizaciones referidas a determinadas categorías, impuestas mediante la declaración formal de zona o área turísticamente saturada, no modifica la consideración de dicha autorización como acto reglado, puesto que, en estos casos tampoco efectúa la Administración una valoración singularizada sobre las nuevas autorizaciones. En estos supuestos la función que corresponde a la Administración se concreta en la aplicación a cada caso concreto, de los preceptos que se contengan en el Decreto de declaración de área turísticamente saturada, que serán de general aplicación a todas las solicitudes de nuevas autorizaciones, en función del contenido que establezca la normativa de limitación referida.

En este sentido no debemos dejar de mencionar las medidas de limitación impuestas en la Comunidad Autónoma Balear dirigidas a actuar frente a la excesiva concentración de plazas hoteleras en determinadas zonas del territorio y contra el gran número de establecimientos obsoletos. En esta Comunidad Autónoma se procedió a través de Planes de Ordenación de la Oferta Turística, en aplicación de la Legislación de Ordenación del Territorio, a dictar medidas transitorias aplicables a las nuevas autorizaciones de establecimientos turísticos ${ }^{66}$. En virtud de estas medidas, las nuevas autorizaciones quedaban limitadas a determinadas categorías (para los establecimientos hoteleros, sólo a hoteles de cuatro y cinco estrellas) y condicionadas a la baja de establecimientos obsoletos preexistentes. Además se acometió el correspondiente Plan de Modernización de Establecimientos Hoteleros. Sin intención de entrar a analizar en profundidad las citadas medidas, pues ello excede del objeto del presente trabajo, sí podemos considerarlas como un conjunto de instrumentos de intervención de singular intensidad en el sistema de autorización y clasificación de los establecimientos hoteleros encaminado a ordenar la oferta turística de una determinada zona del territorio (ejemplo claro, como después se verá, del carácter de autorización operativa).

\subsection{Autorización de funcionamiento}

Por otra parte, el acto de autorización y clasificación de los establecimientos hoteleros es una particular autorización de funcionamiento o de trac-

\footnotetext{
66 Singularmente por medio del Decreto 9/1998, de 23 de enero, de medidas transitorias relativas al procedimiento de expedición de autorizaciones previas y de apertura de construcciones, obras e instalaciones de empresas y actividades turísticas, transformado posteriormente en Ley 4/1998, de 19 de mayo.
} 
to sucesivo, puesto que su otorgamiento provoca una relación continuada entre la Administración turística y el establecimiento autorizado que se proyecta de forma permanente sobre el desarrollo de la actividad hotelera, a lo largo de toda su existencia. Así, desde el momento de otorgarse la autorización se establece un vínculo permanente entre la Administración y el establecimiento que se concreta, principalmente, en la aplicación de un conjunto relevante de deberes jurídico-públicos, cuya comprobación y, en su caso, acción punitiva en vía administrativa, corresponde, por determinación legal, a la propia Administración: obligaciones relativas a la declaración de precios y a las hojas de reclamaciones; comunicar las modificaciones sustanciales que se lleven a cabo en el establecimiento y en los datos que del mismo constan en el Registro de Turismo (Tales como, nombramiento y cese del director; cambios en la titularidad del establecimiento o explotación; modificación de la denominación del establecimiento; alteración en el periodo de funcionamiento; etc.); adaptación a las hipotéticas modificaciones normativas; mantenimiento de las instalaciones y servicios en las adecuadas condiciones de calidad, conforme a la clasificación obtenida; remisión de información y documentación requerida por la Administración; etc. El fundamento del papel que en relación con las empresas hoteleras corresponde a la Administración se encuentra en un conjunto de potestades o facultades administrativas de actuación que el ordenamiento le encomienda a ésta: autorizatoria; de registro y certificación; de inspección; de revocación de la autorización por incumplimiento de las condiciones que se tuvieron en cuenta para su otorgamiento; sancionadora; de requerimiento de información; etc.

Consecuencia del carácter de autorización de funcionamiento es la tipificación como infracción, en sus diferentes niveles de gravedad, de las actuaciones u omisiones de la empresa o establecimiento que impliquen incumplimiento de obligaciones jurídico-públicas, particularmente las que se refieren a las relaciones entre el establecimiento y la Administración o de aquellas otras en las que la Administración asume legalmente la función de garante, aunque se refieran a relaciones del establecimiento con terceros, especialmente, con los usuarios turísticos. Así, podemos destacar, entre las que resultan más significativas:

- La utilización de denominaciones, distintivos o placas de identificación que no se correspondan con la autorización y/o clasificación o especialización otorgada por la Administración.

- Carencia de las hojas de reclamaciones o la negativa a facilitarlas a los clientes que la hayan solicitado, sin causa justificada.

- Percepción de precios superiores a los notificados a la Administración. Incumplimiento de la normativa en materia de precios. 
- Obstrucción a la labor que desarrollen los servicios de inspección turística en el ejercicio de las funciones que le encomienda la Ley.

- Negativa a facilitar a la Administración información relativa a la actividad turística desarrollada, siempre que legalmente sea exigible. Facilitar información errónea o falsa a la Administración.

- Modificación de las condiciones que determinaron la autorización y/o clasificación sin cumplir los trámites requeridos para ello.

- Incumplimiento de las prescripciones impuestas por la normativa turística en materia de prevención y extinción de incendios.

- Realizar la actividad propia del alojamiento hotelero careciendo de la preceptiva autorización administrativa turística (Actividad clandestina).

- No disponer de las instalaciones o servicios preceptivos conforme a la normativa turística respecto a su clase y categoría o disponer de ellos en mal estado de funcionamiento o conservación.

- Efectuar reformas sustanciales o estructurales en el establecimiento sin la obtención previa de la autorización de la Administración competente.

\subsection{Autorización de carácter real}

Por otra parte, la autorización y clasificación de los establecimientos hoteleros se enmarca dentro de las autorizaciones de carácter real, puesto que los elementos que justifican su otorgamiento se refieren a determinadas condiciones objetivas que se requieren de las instalaciones y los servicios del establecimiento, y en ningún caso a cualidades personales del solicitante, como ocurre en las autorizaciones personales. De esta forma, el Decreto 47/2004, de clasificación hotelera de Andalucía, en los apartados 3 y 4 del art. 19 establece:

3. Todos los establecimientos hoteleros habrán de reunir los requisitos mínimos de carácter común que se regulan en este capítulo y los requisitos mínimos de carácter específico que, según el grupo, la categoría y la modalidad a que pertenezcan, se disponen en los anexos 1 a 5 del presente Decreto.

4. La clasificación de los establecimientos hoteleros en grupos, categorías, modalidades y, en su caso, especialidades, se mantendrá en vigor en tanto subsistan las circunstancias que la originaron. En caso contrario, la Consejería de Turismo y Deporte procederá a su revisión, de oficio o a instancia de parte interesada, previo informe del Consejo Andaluz del Turismo, garantizándose en todo caso la audiencia del titular del establecimiento. 
Por tanto, a tenor de lo establecido en este artículo, al igual que ocurre en los restantes Reglamentos autonómicos, la autorización y clasificación de los establecimientos hoteleros se fundamenta, por un lado, en el cumplimiento de requisitos mínimos, impuestos a todos ellos con independencia de la categoría, y, por otro, en condicionantes de la categoría que desee ostentar el establecimiento. Por ello, el mantenimiento de la categoría se condiciona al continuado cumplimiento de dichos requisitos. Los elementos que se tienen en cuenta para otorgar la autorización y clasificación, conforme a la normativa andaluza que nos sirve de modelo, son, por tanto, a) Requisitos mínimos, entre los que se encuentran, el plan de autoprotección; accesibilidad; accesos; insonorización; luminosidad; eliminación de residuos sólidos; salubridad y potabilidad del agua; tratamiento y evacuación de aguas residuales, instalaciones de aguas grises, regeneradas y pluviales y eficiencia energética; y, b) Requisitos a determinar conforme a la categoría del establecimiento, referido a zonas de comunicación (accesos, vestíbulos, ascensores, pasillos y escaleras); zonas de usuarios (habitaciones, baños, aseos generales, comedores y salones); zona de servicios (cocina, cámaras frigoríficas, bodega y despensa, oficios de plantas, depósito de equipaje); zona de personal (vestuarios, aseos, comedor y dormitorio); garaje; instalaciones y servicios (climatización, agua caliente, teléfono, Internet, recepción y conserjería, limpieza, servicio de habitaciones, de restauración, de lavandería, sanitarios, seguridad, mantenimiento, etc.). Como puede observarse se trata de aspectos técnicos referidos a las instalaciones y servicios. En ningún caso la normativa establece elementos personales relativos a la titularidad de la explotación hotelera.

\subsection{Autorización operativa}

Finalmente, entendemos que nos encontramos ante una autorización de carácter operativo, en la que durante el desarrollo de la actividad autorizada (y con independencia de su duración), ésta queda condicionada al mantenimiento de las circunstancias que motivaron su otorgamiento, pudiendo por tanto la Administración efectuar los controles, seguimientos e inspecciones que considere oportunos y conservando la facultad de revocación de la autorización si dejaran de cumplirse las circunstancias que conllevaron su concesión. Como afirman GARCÍA DE ENTERRÍA y FERNÁNDEZ RODRÍGUEZ, las autorizaciones operativas "sin renunciar a la función primaria de control, que también canalizan, pretenden ir más allá de ella encauzando y orientando positivamente la actividad de su titular en la dirección previamente definida por planes o programas sectoriales, o bien, aunque de forma esquemática o, incluso, implícitamente, por la propia norma en cada caso aplica- 
ble" ${ }^{\prime 67}$. Este tipo de autorizaciones cobra singular relevancia en sectores como el turístico, con una constante tendencia a los cambios, a la adaptación a las nuevas tecnologías, a las inquietudes de una demanda en continua evolución, a la política de calidad y competitividad, etc. Por ello, el ordenamiento otorga determinadas facultades a la Administración, en orden a hacer efectiva esta facultad de dirección indirecta de la oferta hotelera, tales como la potestad reglamentaria, de fomento, de planificación, de inspección, sancionadora, etc ${ }^{68}$. La normativa turística de las Comunidades Autónomas insiste en dos aspectos que resultan esenciales en consonancia con la operatividad de la autorización: la necesidad de mantener de forma continua y permanente los requisitos y condiciones que justificaron la autorización y clasificación, así como la obligación de adaptarse a los cambios normativos que, en dicho sentido, apruebe la Administración. De esta forma, los cambios en la normativa hotelera suelen implantarse, en los establecimientos autorizados con sujeción a la normativa anterior, tras un periodo transitorio de adaptación, pudiendo acceder, incluso, a vías de financiación públicas. Así, por ejemplo, la adaptación de los establecimientos hoteleros en funcionamiento al nuevo Decreto de clasificación de establecimientos hoteleros de Andalucía se establece de forma escalonada en seis meses, uno, dos y cuatro años ${ }^{69}$. También se prevé en dicha normativa la convocatoria de subvenciones dirigidas a apoyar las adaptaciones, determinando, en su disposición adicional primera, que:

La Consejería de Turismo y Deporte podrá acordar medidas de fomento dirigidas a que los establecimientos hoteleros inscritos en el Registro de Turismo de Andalucía adapten sus instalaciones al presente Decreto, especialmente en lo relativo a las medidas medioambientales, energéticas y de accesibilidad.

El carácter operativo del acto de autorización y clasificación hotelera aparece delimitado con mayor precisión en la normativa de la Comunidad Autónoma de Baleares. En efecto, como hemos comentado anteriormente, debido

${ }^{67}$ Curso de Derecho Administrativo, Vol. II, $7^{\mathrm{a}}$ ed., Cívitas, Madrid, 2001, pp. 138-139.

68 Para CALONGE VELÁZQUEZ, A., "La Administración no sólo verifica un juicio de oportunidad respecto a la iniciativa propuesta por el particular, sino que además se interesa y controla cada una de las modalidades de ejercicio en que se desarrolla tal iniciativa, con lo que su control no se limita, sino que se extiende en el tiempo mientras dura la actividad económica prevista”. En El turismo: Aspectos institucionales y actividad administrativa, op. cit., pp. 174-175.

${ }^{69}$ Vid. Disposición Transitoria Segunda. 
a la situación de saturación y obsolescencia que presentaba la planta hotelera de Baleares, se adoptó un conjunto de medidas legales y reglamentarias, de gran repercusión en la oferta hotelera. Destacaremos, entre todas ellas, la Ley 3/1990 de 30 de mayo, por la que se crea y regula el Plan de Modernización de los Establecimientos Turísticos, que impuso una inspección técnica de los establecimientos que contaran con cierta antigüedad, y su sujeción, en caso oportuno, a un Plan de Modernización ${ }^{70}$. Este procedimiento podía finalizar con la realización de las obras de modernización por parte de la empresa o mediante resolución impositiva del Consejero de Turismo. En caso de oposición, la Administración podía ordenar la clausura del establecimiento. El éxito de estas medidas, impulsó su inclusión en la Ley 2/1999, General de Turismo, con ciertas modificaciones sobre el modelo de 1990, con la figura del «plan de modernización permanente»:

1. Todos los establecimientos, actividades y empresas sometidos a autorización turística deberán superar el Plan de modernización permanente que establezca la Administración en los plazos que se fijen.

2. Será requisito imprescindible para la superación de los distintos planes de modernización permanente, el cumplimiento de lo dispuesto en la Ley 3/1993, de 4 de mayo, de mejora de la accesibilidad y supresión de las barreras arquitectónicas, independientemente del plazo máximo establecido en la disposición transitoria primera de la citada Ley.

3. La no superación de algún aspecto sustancial de los planes de modernización conllevará la clausura del establecimiento y la revocación de las autorizaciones turísticas. Este hecho deberá ser notificado al propietario y al explotador del establecimiento.

También podemos destacar, como singulares manifestaciones del carácter operativo de la autorización hotelera, las prescripciones impuestas por la Ley de Turismo de Canarias, en relación con la conservación de la calidad de los establecimientos alojativos (Art. 44), particularmente, la sujeción de los establecimientos con más de diez años de antigüedad a un programa especial de mantenimiento "destinado a la incorporación de soluciones técnicas actuali-

\footnotetext{
${ }^{70}$ Vid. BLASCO ESTEVE, J., "Planificación y gestión del territorio turístico en las Islas Baleares", en BLANQUER CRIADO, D., Ordenación y gestión del territorio turístico, Tirant lo Blanch, Valencia, 2002, pp. 215-284 y SOCÍAS CAMACHO, J.M., "La modernización y reconversión de las zonas turísticas", en GARCÍA MACHO, R., y RECALDE CASTELLS, A., Lecciones de Derecho del Turismo, Tirant lo Blanch, Valencia, 2000, pp. 119-155.
} 
zadas", al que pueden sumarse establecimientos más recientes que presenten síntomas importantes de deterioro. A la superación del programa se supedita el mantenimiento de la clasificación que viniera disfrutando el establecimiento. También es expresión manifiesta de la operatividad el contenido del art. 44,4 de dicha Ley:

Sin perjuicio de lo establecido en los apartados anteriores, los Ayuntamientos y, subsidiariamente la Consejería competente en materia turística podrán en cualquier momento requerir a los titulares de los establecimientos turísticos la ejecución de obras de conservación y mejora de las fachadas o espacios visibles desde la vía pública.

Sin embargo, la mayor incidencia en el sistema de clasificación de la Comunidad Autónoma de Canarias es, a nuestro juicio, la provocada por los Planes Insulares, que llegan a imponer determinadas categorías para las nuevas solicitudes de autorización de establecimientos de alojamiento turístico ${ }^{71}$.

\section{El acto administrativo de dispensa como manifestación discrecional de la facultad de ordenación del turismo a través de la clasificación de los esta- blecimientos}

En el procedimiento de tramitación de la autorización y clasificación de los establecimientos hoteleros, al igual que ocurre con otros establecimientos de alojamiento turístico, se introduce una flexibilización del sistema clasificatorio al regularse la figura de la dispensa del cumplimiento de determinado o determinados requisitos referidos a la categoría a la que aspira el establecimiento solicitante. Esta dispensa de requisito es un acto administrativo expreso $^{72}$, motivado, y dictado a instancia de parte, por el que la Administración, de forma justificada exime del cumplimiento de alguno o algunos de los requisitos que la normativa impone a una determinada categoría de establecimiento hotelero. La doctrina incluye las dispensas entre los actos favorables al intere-

${ }^{71}$ Vid., al respecto, el trabajo de SUAY RINCÓN, J., titulado "Turismo y urbanismo: la ordenación turística del espacio. El caso de Canarias", en BLANQUER CRIADO, D., Ordenación y gestión del territorio turístico, op. cit., pp. 287-348.

${ }^{72} \mathrm{El}$ acto de dispensa puede producirse de forma independiente a la autorización y clasificación o de forma conjunta. El art. 12,1 del Reglamento Hotelero de la Comunidad de Madrid, por ejemplo, impone la resolución conjunta de las tres cuestiones. 
sado $^{73}$, otorgados en ejercicio de una potestad discrecional ${ }^{74}$, pues la Administración la concederá o no tras efectuar una valoración de los elementos y circunstancias concomitantes, a la luz del correspondiente informe técnico (impuesto habitualmente como preceptivo) y, en ningún caso, puede convertirse en un derecho del solicitante. Las Leyes de Turismo suelen considerarlo como una facultad excepcional de la Administración ${ }^{75}$, que no puede, por tanto, generar un derecho en el administrado. El objeto de dispensa queda igualmente delimitado por el ordenamiento jurídico a requisitos de clasificación, no a los que correspondan al ejercicio de la actividad. Esta cuestión es resuelta con claridad en algunas Leyes de Turismo, como ocurre con la correspondiente a Castilla-La Mancha, en cuyo art. 12 se limita la dispensa a "alguna de las exigencias técnicas requeridas para su clasificación, sin que en ningún caso pueda suponer la exención de las condiciones y requisitos necesarios para el ejercicio de su actividad". Otras Leyes se limitan a considerar como dispensable los «requisitos de clasificación ${ }^{76}$, aunque, en ocasiones, el objeto de dispensa aparezca diluido en algunas disposiciones legales. Así ocurre, por ejemplo, en la Ley de Turismo de Aragón que se refiere a "alguno de los requisitos mínimos exigidos por los reglamentos de desarrollo de esta Ley" (Art. 29,3) y en la Ley de Turismo de Galicia centrada en el "cumplimiento de alguno de ellos (requisitos técnicos mínimos) cuando así lo aconsejen sus características especiales" (Art. 29,3). En términos similares de ambigüedad se manifiestan las Leyes de Turismo del Principado de Asturias ${ }^{77}$, Región de Murcia ${ }^{78}$ o Canarias $^{79}$.

73 PARADA VÁZQUEZ, R., Derecho Administrativo I. Parte general, Marcial Pons, Madrid, 2004, p. 109.

${ }^{74}$ En el mismo sentido, SANZ SALLA, C.O., op. cit., p. 88.

75 Con tal carácter aparece regulado en las Leyes de Turismo de Andalucía (Art. 31,2); Castilla-La Mancha (Art. 12); Extremadura (Art. 15) y Principado de Asturias (Art. 27,3).

${ }^{76}$ Así se recoge en el art. 15 LT Extremadura; art. 31,2 LT Andalucía y art. 16,3 LT Navarra.

77 Art. 27,3 "ser objeto de dispensa de alguno de los requisitos mínimos exigidos reglamentariamente en materia turística".

78 Art. 25: "de la aplicación de alguna de las condiciones mínimas establecidas en la presente Ley o normas complementarias que la desarrollen”.

${ }^{79}$ Art. 34: "podrá eximir del cumplimiento de los estándares de aplicación, a los proyectos de nueva construcción". 
La articulación de la facultad de dispensa debe efectuarse con las máximas garantías de legalidad e igualdad. Sólo puede aplicarse en las casos previstos por la Ley, sin que su práctica pueda poner en peligro el valor de los criterios objetivos de clasificación impuestos por vía reglamentaria y, por tanto, atentar contra el principio de igualdad, o suponer una vulneración del principio de inderogabilidad singular de los reglamentos. Por estas razones, se hace preciso, como se ha indicado, la emisión de informe técnico, que se presupone habrá de ser favorable (si bien este extremo no consta de forma expresa en la Ley); la justificación o motivación de su concesión, a tenor de lo establecido con carácter general por el art. 54 Ley 30/1992, de Régimen Jurídico de las Administraciones Públicas y Procedimiento Administrativo Común, para los actos dictados en ejercicio de potestades discrecionales y, en ocasiones, se impone una previa valoración compensatoria, en tanto en cuanto el requisito incumplido quede «equilibrado», por la concurrencia de otros condicionantes en los que el establecimiento supere la barrera impuesta por la norma. En efecto, la Ley de Turismo de Navarra determina su concesión "cuando las circunstancias concurrentes permitan compensar el incumplimiento con la valoración conjunta de sus instalaciones y de las mejoras que pueda introducir" (Art. 16,3). En el mismo sentido la LT de la Región de Murcia justifica su otorgamiento "siempre que la valoración conjunta de sus instalaciones, servicios y mejoras que pueda introducir así lo aconseje, en la forma que reglamentariamente se determine" (Art. 25). Se trata, sin duda, de garantizar, por una parte, la aplicación plena del principio de igualdad frente a la Ley y, por otra, que el sistema de clasificación no quede desvirtuado por prácticas no suficientemente justificadas y compensadas. En definitiva, los niveles de calidad que la norma impone a través del sistema administrativo de clasificación, deben salvaguardarse incluso frente a la facultad de dispensa, que no deja de configurarse como instrumento excepcional en la ordenación de las empresas de alojamiento turístico.

Por otra parte, es preciso resaltar que la dispensa, tanto en su solicitud como en su otorgamiento, debe fundamentarse en razones que justifiquen su concesión, y no en el mero incumplimiento de determinado o determinados requisitos. Así, para la LT de Canarias habrán de concurrir "razones de interés turístico debidamente acreditado en el expediente" (Art. 34) o quedar justificada específicamente para los supuestos de rehabilitación de inmuebles para uso turístico "con la finalidad de preservar y recuperar el patrimonio arquitectónico aragonés como seña de identidad del turismo de la Comunidad Autónoma" (Art. 29,3 LT Aragón) ${ }^{80}$.

${ }^{80}$ La dispensa de requisitos en inmuebles de valor histórico-artístico o monumental, justificada precisamente en la imposibilidad de acometer determinadas reformas, será recogida de forma reiterada por las Leyes de Turismo. La LT Galicia en su art. 29,3 determina que "Especialmente 
El desarrollo reglamentario de la dispensa de requisitos a los establecimientos hoteleros mantiene las consideraciones establecidas en la Ley en cuanto a su excepcionalidad, justificación y compensación respecto a los restantes requisitos y condiciones que cumpla el establecimiento, imponiendo, en este sentido, una valoración conjunta del establecimiento en cuanto a instalaciones y servicios ${ }^{81}$. Por otra parte, los Reglamentos de ordenación y clasificación de los establecimientos hoteleros desarrollan determinados aspectos de la dispensa, tratando en algunos casos, supuestos muy específicos. Del desarrollo reglamentario de la dispensa podemos destacar los siguientes aspectos:

- La dispensa queda delimitada a requisitos vinculados al grupo, modalidad o categoría del establecimiento.

- Se contempla como supuesto general que justifica la dispensa, el tratarse de edificios con singular valor histórico-artístico, monumental o cultural, que impida, por tal motivo, efectuar determinadas obras de adaptación del inmueble para su uso como alojamiento turístico hotelero $^{82}$.

- Por igual motivo que el expresado en el apartado anterior, se regula en algunos supuestos, la dispensa para establecimientos especializados, principalmente como monumento, rural o típico, con objeto de facilitar la existencia de este tipo de instalaciones ${ }^{83}$.

- En algunas reglamentaciones se prevé la dispensa de los requisitos relativos a calefacción, refrigeración o climatización en establecimientos

podrá hacerse uso de esta facultad cuando se trate de establecimientos de alojamiento ubicados en edificios de especial relevancia histórico-artística". También la LT Principado de Asturias se refiere a la dispensa con la finalidad de "preservar y recuperar el patrimonio arquitectónico" en la rehabilitación de inmuebles para uso turístico (Art. 27,3).

81 "Asimismo, podrá hacer uso de esta facultad de dispensa ponderando la calidad y demás condiciones de las existentes en los establecimientos, de manera que se compensen las carencias objeto de dispensa" (Art. 13,5 RH Galicia).

${ }^{82}$ En Galicia esta justificación se aplica a los espacios naturales: "Especialmente se podrá hacer uso de esta facultad cuando se trate de establecimientos de alojamiento situados en espacios naturales y en edificios de especial relevancia histórico-artística de la Comunidad Autónomas gallega" (Art. 13,5 in fine RH Galicia).

${ }^{83}$ Es la postura adoptada por RH Cataluña o en Extremadura: "Los hoteles especiales de montaña, moteles, hoteles-monumentos y hoteles típicos-rurales gozarán de las dispensas que reglamentariamente se fijen" (Art. 6,3 RH Extremadura). 
de temporada, que por su ubicación y temperatura ambiente, no precisen dicha instalación ${ }^{84}$.

- También se prevé la dispensa en los procesos de adaptación de los establecimientos existentes a los condicionantes impuestos por cambios normativos, siempre que se justifique plenamente su concesión ${ }^{85}$.

- Algunas disposiciones regulan e incluso prohíben la concesión de dispensa en relación con requisitos de seguridad de los establecimientos. Especialmente lo determina el Reglamento del País Vasco: "cuando la medida de dispensa se refiera a instalaciones, servicios o a elementos que pudieran afectar o tener incidencia en la seguridad del edificio, deberán adoptarse otras soluciones alternativas que garanticen la seguridad del mismo y así se haga constar por las entidades que intervengan preceptivamente en el visado técnico, la supervisión y el informe del proyecto, cuando consideren suficientemente justificada, técnica y documentalmente su necesidad, derivada de la singularidad del proyecto" 86 .

Finalmente, el tratamiento de la dispensa presenta connotaciones especiales en los Reglamentos de ordenación y clasificación de establecimientos hoteleros de Navarra, Andalucía y Comunidad de Madrid. El primero de ellos, por establecer la dispensa como mecanismo excepcional a través del cual un establecimiento puede acceder a una categoría superior a la que ostente, con objeto de incrementar la calidad de los establecimientos: "Sin perjuicio de la modificación de la clasificación otorgada que pueda solicitarse cuando se cumplan los requisitos que exige este Reglamento para las diferentes categorías, los hoteles, hoteles rurales y hoteles apartamentos podrán solicitar, por una sola vez y dentro de cada modalidad, su clasificación en la categoría inmediata superior a la que les corresponde, de acuerdo con el sistema excepcional que se establece en este apartado”. (Anexo 2. RH Navarra).

${ }^{84}$ Art. 68 RH Cantabria; art. 2,2 RH Castilla y León; art. 84 RH Galicia y art. 25 RH La Rioja. Este último determina, para los establecimientos de temporada que "podrán ser dispensados de la obligación de instalar calefacción o refrigeración o ambas, cuando estén situados en lugares que durante la temporada de funcionamiento la temperatura ambiente no lo requiera" (Art. 25,2).

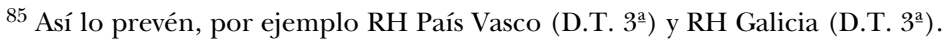

${ }^{86}$ Conforme determina el art. 35 in fine del RH Región de Murcia, "No serán objeto de dispensa alguna las medidas mínimas de seguridad, calidad de los materiales a emplear y las que supongan un menoscabo de la prestación del servicio". 
Por su parte, en el RH de Andalucía, según se ha mencionado supra, se incorpora como elemento adicional a valorar en el otorgamiento de la dispensa, que el establecimiento utilice energías renovables o "por la incorporación de otras instalaciones y medidas tendentes a la mejora del medio ambiente". De esta forma, la Administración procura compensar la concesión de la dispensa, resaltando su carácter extraordinario, con la introducción de mejoras al medio ambiente.

Finalmente, el RH de la Comunidad de Madrid es, hasta ahora, la única disposición que establece límites cuantitativos específicos a la facultad de dispensa de que goza la Administración, determinando en su art. 15:

La facultad de dispensa, en lo que afecte a los requisitos mínimos exigidos en habitaciones y cuartos de baño, salvo en los supuestos contemplados en el apartado segundo del artículo anterior ${ }^{87}$, se ejercerá, en su caso, siempre que existan razones técnicas debidamente acreditadas y de acuerdo con los siguientes criterios:

a) La superficie mínima exigible para las habitaciones, baños o aseos, según categoría, no podrá ser objeto de dispensa cuando suponga una reducción superior al 15 por 100 de tal superficie.

b) Las dispensas a que se refiere el anterior apartado a) sólo se concederán con mantenimiento de la categoría pretendida, cuando afecten a menos del 50 por 100 de las habitaciones o de los baños o aseos.

c) Sólo por razones muy cualificadas, de las que exista constancia documental significativa, podrán interpretarse los porcentajes de los apartados precedentes como indicativos, admitiéndose variaciones leves y excepcionales plenamente justificadas.

\section{Especial referencia a la reclasificación de los establecimientos y a la revo- cación de la autorización}

El acto administrativo de otorgamiento de clasificación a un establecimiento hotelero se encuentra condicionado de forma permanente al mantenimiento de los requisitos que se tuvieron en cuenta, conforme a la normativa vigente, para su concesión. Así, el art. 9 del Decreto 153/1990, de 11 de diciembre, de clasificación hotelera de Aragón establece que:

${ }^{87}$ Establecimientos hoteleros ubicados en edificios especialmente protegidos, en su totalidad o parcialmente, por sus valores arquitectónicos, históricos o artísticos, a los que no se les aplican estas limitaciones. 
La clasificación otorgada se mantendrá en tanto sean cumplidos los requisitos que se han tenido en cuenta al efectuar aquélla, pudiendo revisarse de oficio a petición de parte.

Toda modificación que se realice en un establecimiento y que afecte al cumplimiento de las normas contenidas en el presente Reglamento deberá comunicarse a la Administración para su aprobación o reclasificación si procede.

Deviene, por tanto, una obligación por parte de la empresa de mantener las condiciones requeridas de calidad en las instalaciones, así como en la prestación de los servicios a los usuarios turísticos, conforme a la categoría, modalidad y, en su caso, especialidad del establecimiento. Esta circunstancia no es más que fiel reflejo, como se indicó anteriormente, del carácter de autorización de funcionamiento de que goza la autorización y clasificación hotelera. Pero, además, la normativa impone una constante adaptación de los establecimientos a los cambios normativos que se lleven a cabo a lo largo del tiempo en que el establecimiento permanezca en funcionamiento ${ }^{88}$. El ordenamiento prevé para estas situaciones tres tipos de medidas. Por una parte, la fijación de un periodo transitorio de adaptación en el cual los establecimientos autorizados conforme a la anterior normativa vigente han de efectuar las modificaciones precisas para adecuar sus instalaciones a la nueva regulación normativa y proceder a notificar dicha circunstancia a la Administración. En este sentido resulta clarificador el art. 31,4 LT Andalucía:

Cuando los requisitos exigidos para su otorgamiento sean modificados como consecuencia de cambios normativos, los titulares de los establecimientos turísticos gozarán de un plazo de adaptación para el mantenimiento de su clasificación; si los titulares no efectuaran la adaptación, la Consejería otorgaría la procedente.

En segundo lugar, la Administración suele efectuar convocatorias de ayudas y subvenciones o créditos preferentes para financiar las obras de adapta-

${ }^{88}$ Afirman, en este sentido, GARCÍA DE ENTERRÍA y FERNÁNDEZ RODRÍGUEZ, que "Las autorizaciones de funcionamiento responden, en efecto, con carácter general al esquema de los actos-condición; son, pues, títulos jurídicos que colocan al administrado en una situación impersonal y objetiva, definida abstractamente por las normas en cada caso aplicables y libremente modificables por ellas, una situación, en fin, legal y reglamentaria, cuyo contenido, en su doble vertiente, positiva y negativa (derechos y obligaciones), hay que referir en cada momento a la normativa en vigor. Op. cit., p. 142. 
ción que fueran precisas, siempre que éstas se encuentren motivadas precisamente en la necesaria acomodación a la nueva normativa. En este sentido, podemos enunciar lo establecido en la Disposición Adicional Primera del Decreto 47/2004, de establecimientos hoteleros de Andalucía:

La Consejería de Turismo y Deporte podrá acordar medidas de fomento dirigidas a que los establecimientos hoteleros inscritos en el Registro de Turismo de Andalucía adapten sus instalaciones al presente Decreto, especialmente en lo relativo a las medidas medioambientales, energéticas y de accesibilidad.

En ocasiones se otorga una mención especial a los establecimientos que se adaptan a las nuevas previsiones legales o a los planes de modernización que aprueba la Administración, como ocurre con los denominados «establecimientos modernizados» implantados en Baleares ${ }^{89}$.

La tercera medida que se contempla con finalidad coactiva es la posibilidad de imponer una reclasificación de oficio del establecimiento, si una vez transcurrido el periodo transitorio no se efectúan las obras de adaptación, con lo que aquél sería clasificado por la Administración conforme a los requisitos que efectivamente cumpla con arreglo a la normativa vigente en dicho momento (Vid. Art. 31,3 LT Andalucía, recogido supra) ${ }^{90}$.

${ }^{89}$ La Ley 3/1990, de 30 de mayo, por la que se crea y regula el Plan de Modernización de alojamientos turísticos existentes en Baleares, impone la sujeción a una inspección técnica preceptiva, conforme a las previsiones del Plan. Una vez superada dicha inspección y efectuadas, en su caso, las obras de adaptación que fueran precisas, la Consejería otorga autorización para utilizar la denominación y el distintivo de «hotel modernizado» o «apartamento modernizado» (Art. 6). Vid. BLANQUER CRIADO, D., "La ordenación jurídica de la calidad del turismo", op. cit., p. 3161.

${ }^{90}$ Vid., en el mismo sentido, la disposición transitoria segunda de los Reglamentos de Clasificación Hotelera de Andalucía, País Vasco y Galicia. A tenor de este último: "1. Los establecimientos hoteleros existentes a la entrada en vigor de este Decreto que cuenten con la preceptiva autorización turística de apertura y clasificación, así como los mencionados en la anterior disposición, que se encuentren clasificados en alguno de los grupos o categorías a que hace referencia este Decreto dispondrán de un plazo máximo de cinco años para adaptar sus instalaciones y servicios a la categoría que ostenten. A estos efectos tendrán prioridad en la concesión de subvenciones que periódicamente pudiera anunciar la Consellería competente en materia de turismo. 2. De no realizarse la adaptación mencionada en el número anterior, el centro directivo correspondiente de la Consellería competente en materia de turismo, procederá de oficio, bien por propia iniciativa o por propuesta de las correspondientes delegaciones provinciales de la citada Consellería, tras la audiencia al interesado, a reclasificar el establecimiento en el grupo y categoría que le corresponda de acuerdo con las disposiciones de este Decreto". 
Además de la reclasificación de oficio, efectuada una vez transcurrido el periodo transitorio de adaptación a las modificaciones normativas o como fruto de las deficiencias detectadas mediante la intervención de la inspección turística, el ordenamiento regula la reclasificación como derecho que corresponde al titular del establecimiento (o de su explotación) de efectuar las reformas oportunas en sus instalaciones y la mejora en los servicios que se preste a los usuarios, con objeto de obtener una clasificación superior a la que detentaba el establecimiento con anterioridad, conforme al acto inicial de autorización y clasificación. Así se recoge, por ejemplo, en el art. 34 del Decreto 111/2003, de desarrollo de la Ley de Turismo de La Rioja:

Los titulares de los establecimientos hoteleros podrán solicitar de la Consejería competente en materia de turismo la reclasificación de aquéllos a una categoría superior o inferior a la que tuviesen otorgada, aportando para ello los documentos relacionados en el artículo 31, que deberá ser resuelta en el plazo de tres meses a contar desde la fecha en la que la solicitud hubiera tenido entrada en el registro de la citada consejería.

De nuevo nos encontramos ante una manifestación propia de las autorizaciones de funcionamiento, en la que el contenido de ésta puede alterarse a instancia de parte. Esta técnica se ve favorecida por el ordenamiento jurídico ante la posibilidad de alcanzar a través de ella una mejora en la calidad de los establecimientos, pudiendo llegar a ser objeto de incentivos administrativos dirigidos a elevar la categoría de los establecimientos de alojamiento turístico, por medio de planes de modernización; planes de calidad; subvenciones y ayudas para la mejora de las instalaciones que impliquen un incremento en la categoría; etc. ${ }^{91}$.

Junto a la reclasificación aparece la revocación de la autorización. La legislación turística contempla el acto de revocación de la autorización desde una doble perspectiva: bien como potestad de la Administración por incumplimiento de los requisitos que se tuvieron en cuenta para su concesión; bien como sanción ante infracciones muy graves ${ }^{92}$. La diferencia entre una figura y

${ }^{91}$ En este sentido, el art. 73 de la Ley de Turismo de Galicia, por ejemplo, incluye entre los objetivos de los programas dirigidos a potenciar la oferta turística de la Comunidad Autónoma, facilitar "la reclasificación de las empresas turísticas en grupos o categorías superiores".

${ }^{92}$ Para FERNÁNDEZ RODRÍGUEZ, C., "La revocación de la autorización no acostumbra por ello a plantearse en las legislaciones autonómicas como una sanción, sino como consecuencia de efecto resolutorio derivado del incumplimiento de las condiciones en virtud de las cuales se otor- 
otra resulta realmente compleja, pero de gran relevancia, puesto que el régimen jurídico aplicable a cada situación es completamente diferente. Así, en la revocación-sanción será precisa la existencia de un procedimiento sancionador y la estricta sujeción al principio de legalidad, particularmente en cuanto se refiere a la tipificación de la infracción y a la correspondiente sanción de revocación del título o licencia. En cambio, la revocación por incumplimiento de los requisitos que justificaron el otorgamiento de la autorización, implica la mera aplicación de una condición resolutoria incorporada al propio acto de autorización. Como ha puesto de relieve el Tribunal Supremo, este tipo de acto-condición es frecuente en el caso de las autorizaciones de funcionamiento $^{93}$ :

Resulta especialmente significativa, a estos efectos, la distinción entre autorizaciones por operación y autorizaciones de funcionamiento que, como la que corresponde al servicio impropio del taxi, se refieren al desarrollo de una actividad. Estas responden al esquema de actos-condición y son, pues, títulos jurídicos que colocan al autorizado en una situación objetiva, definida abstractamente por las normas aplicables constitutivas de un status complejo. La revocación del título administrativo habilitante aparece, en consecuencia, como una condición resolutoria incorporada al mismo; de tal manera que en caso de verificarse el presupuesto de la condición consistente en el incumplimiento grave de sus obligaciones por parte del sujeto titular de la autorización, sobreviene la consecuencia jurídica de la extinción del acto administrativo por el que se otorgó el título.

Por tanto, estos supuestos de revocación se corresponden con una facultad excepcional otorgada por la Ley a la Administración para anular el acto de autorización y clasificación de los establecimientos hoteleros en el caso de que éstos dejen de cumplir las condiciones y requisitos determinantes de su otorgamiento. Puede considerarse, por tanto, que nos encontramos ante un supuesto de acto administrativo condicionado (autorización condicionada o acto-condición), en el cual, al incumplirse la condición, se resuelve el otorga-

gó inicialmente la autorización", sin embargo, analizando las Leyes de Turismo observamos que éstas contemplan tanto la revocación-sanción, incluyendo dicha medida entre la relación de infracciones tipificadas legalmente, como la revocación por incumplimiento de las condiciones de otorgamiento de la autorización. Vid., Op. cit., p. 205. Igualmente, CEBALLOS MARTÍN, M.M., La regulación jurídica de los establecimientos hoteleros, Marcial Pons, Barcelona, 2002, pp. 193-194.

${ }^{93}$ STS de 8 de octubre de 2001, AR 5862. En el mismo sentido, STS de 16 de junio de 1980 , AR 3195; STS de 14 de mayo de 1998, AR. 4919; STS de 24 de abril de 2000, AR 3375; entre otras. 
miento de la autorización. Este supuesto de revocación de la autorización se recoge de forma expresa en la mayoría de las Leyes de Turismo ${ }^{94}$. Así, el art. 18 de la LT de Cantabria, determina que:

El órgano competente en materia de turismo podrá revocar las autorizaciones y licencias turísticas cuando se incumplan gravemente las condiciones o desaparezcan las causas o las circunstancias de su otorgamiento. Esta revocación se efectuará mediante el oportuno procedimiento, con audiencia del interesado, razonando las causas debidamente y por resolución firme.

Igualmente, la LT de la Región de Murcia establece en su art. 10,3, que:

Las autorizaciones o títulos-licencia podrán ser revocadas, mediante resolución motivada y previa la tramitación del oportuno expediente, cuando se incumpla alguno o algunos de los requisitos que sirvieron de base para su otorgamiento.

En estos supuestos no es preciso, por tanto, iniciar un expediente sancionador, pues la revocación no es una sanción ${ }^{95}$, pero sí el correspondiente procedimiento, en el que deviene como elemento esencial la audiencia al interesado, y en el que la resolución aparezca suficientemente motivada. En este sentido se expresa el Tribunal Supremo: "Que lo expuesto quiere decir que, en esta materia, la Administración podrá declarar caducada la licencia, o bien revocarla, pero no arbitraria, ni discrecionalmente, sino sometiéndose por entero a los requisitos marcados en el ordenamiento, pudiendo llegar a tales conclusiones de caducidad o revocación, sólo cuando las circunstancias concurrentes lo permitan, de acuerdo con las previsiones legales y reglamentarias" ${ }^{\prime 96}$. Con anterioridad a la resolución de revocación de la autorización, que

${ }^{94}$ Además de los ejemplos de Cantabria y Región de Murcia, encontramos referencia expresa a la revocación por incumplimiento de condición en las Leyes de Turismo de Aragón (Art. 26,4); Castilla La Mancha (Art. 3,c); Cataluña (Art. 39,3); Comunidad de Madrid (Art. 22); Principado de Asturias (Art. 25,4) y La Rioja (Art. 9).

${ }^{95}$ La STS de 17 de julio de 2000, AR. 7790, en relación con la licencia de apertura de un barrestaurante, indica que no se trata, en la revocación por incumplimiento de requisitos, de una sanción, sino del incumplimiento del condicionado de la licencia.

96 STS de 16 de junio de 1980, AR. 3195. 
debe aparecer como ultima ratio, la Administración debe instar al establecimiento para que acometa las obras o las modificaciones necesarias para adecuarse a las condiciones por las que se concedió la autorización y clasificación, otorgándole para ello un plazo de tiempo razonable, finalizado el cual, sin alcanzar el objetivo propuesto, podría continuarse el procedimiento de revocación de la autorización.

Por otra parte, es preciso destacar, que las Leyes de Turismo regulan detalladamente la revocación-sanción, bien como sanción principal, bien como accesoria de la principal, normalmente reservada para infracciones muy graves o por reincidencia de infracciones muy graves que, además, impliquen daño relevante a determinados intereses turísticos o a la imagen turística de la Comunidad Autónoma. Así, en la LT de Extremadura (Art. 81,2):

La clausura del establecimiento o la revocación de la autorización o licencia para el ejercicio de la actividad procederá en los casos de reincidencia en la comisión de una falta muy grave, cuando el hecho infractor hubiera lesionado gravemente los intereses turísticos de Extremadura

En el mismo sentido, se manifiesta la LT de Castilla y León (Art. 64,2):

Las sanciones accesorias de cierre definitivo y revocación previstas en el artículo 60, párrafo 2, letra b), se podrán imponer en los casos de reincidencia en la comisión de una falta muy grave, siempre que la infracción hubiese dañado o perjudicado la imagen o los intereses turísticos de Castilla y León.

Sin embargo, este tipo de revocación se enmarca dentro del ejercicio de la potestad sancionadora de la Administración en materia turística y, por tanto, goza de las garantías sustanciales y procedimentales que el ordenamiento prevé en la materia, distinguiéndose del supuesto de revocación por aplicación de condición resolutoria, conforme se ha indicado supra. 